\title{
Alain Kleinberger en Philippe Mesnard (red.), La Shoah. Théâtre et cinéma aux limites de la représentation
}

\section{Anne Roche}

Traducteur : Anneleen Spiessens

\section{(2) OpenEdition}

\section{Journals}

Édition électronique

URL : http://journals.openedition.org/temoigner/1124

DOI : $10.4000 /$ temoigner. 1124

ISSN : 2506-6390

Éditeur :

Éditions du Centre d'études et de documentation Mémoire d'Auschwitz, Éditions Kimé

\section{Édition imprimée}

Date de publication : 1 octobre 2014

Pagination : 164-167

ISBN : 978-2-84174-674-3

ISSN : 2031-4183

Référence électronique

Anne Roche, « Alain Kleinberger en Philippe Mesnard (red.), La Shoah. Théâtre et cinéma aux limites de la représentation », Témoigner. Entre histoire et mémoire [Online], 118| 2014, Online op 01 octobre 2015, geraadpleegd op 23 octobre 2020. URL : http://journals.openedition.org/temoigner/1124 ; DOI : https://doi.org/10.4000/temoigner.1124 


\section{Boekenplank}

\section{OIKOFOBIE:}

DE ANGST VOOR HET EIGENE

Thierry Baudet

Amsterdam: Prometheus/Bert Bakker, 2013, 248 p.

zijn recentste boek, Oikofobie - de angst voor het eigene, werkt de Nederlandse journalist Thierry Baudet in enkele beknopte columns een drieta sellingen uit. De eerste luidt dat het Europese project volkomen heeft gefaald, en dat de instellingen en snel mogelijk these stelt de migration kun these stelt de migratienaar Nederland en de daaraan gekoppelde islamisering aan de kaak. In het kielzog an die stelling wordthet proces tegen P V -politicus (r) justitie en rechtvaardige(r) justitie en een grote(re) vrijheid van in baarheid die de moderne kunst naar zijn mening al een halve euw kentencel vernietiging van het sociale weefsel die de moderniteit met $\mathrm{c}$. ontheend en politek onteigend: dat word onze toomst als de oikofobie niet wordt gestopt.

Misschien vereist een niet-academisch werk geen academische kritiek. Maar de auteur beroept zich (onder meer op zijn website, www.thierrybaude com) op zijn academische vorming. Zijn boek bevat tal van waarheidsclaims, het voetnotenapparat sugde implicatiev van zijn eisen (ante standpunten en crugkeer nar de nationale munt) zijn verreiken, terugkeer naar de nationale munt) zijn verreikend. is is. Maar ze streven ernaar om die waarheid zo dicht mogelijk te benaderen. Daarvoor onderwerpen ze zichbjectiviteit garandeert Indien Baudet oprocht ware uitspraken heeft nagestrefind baudet oprecht ware uitspraken heeft nagestreefd, dan mogen die ook aan etenschappelijke criteria worden getoetst. is niet gangbaar en zou ontleend zijn aan de Britse filo- soof Roger Scruton. Nu komen in filosofische vertogen elk vaker nieuwe termen voor: 'Geworfenheit' (Heidegger), 'capsulaire beschaving' (Lieven De Cauter), of 'de precessie van de simulacra' (Baudrillard). ' Zo proberen filosofen de kleine nuances van een fenomeen te omschrijven, of vatten ze de interactie van meerdere complexe fenomenen samen. Indien ze nauwkeurig afgebakend zijn, zijn de termen erg bruikbaar. Ze voorkomen immers dat meer verfijnde concepten of ideeën .

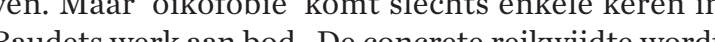
Baudets werk aan bod. De concrete reikwijdte word ziche

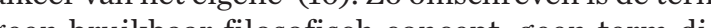
een die is "een "multiculturele" - dat wil zemgen

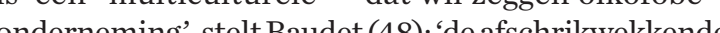
onderneming", stelt Baudet (48); 'de afschrikwekkende (a... komen evenzee voort uit een vijandschap met de Oikos' (9). Alsof de wascing Oene zou kunnen behoren.

Op zich is de titel niet zo'n probleem, ware het nie dat die illustratief is voor de retoriek die het hele boek doort waar pubers doorheen waar pubers doon' (10). Dit impliceert dat weer ove zou moeten gaan' (10). Dit inpliceert dat een volwascrkent, zich mental in erkent, zich mentaal in een puberfase bevindt. Voorstandersvan de EU zijn (naast openlijkefederalisten en leugenaars) 'mensen die het niet begrijpen', wie denk dat Europa uniek in zijn soort is heeft weinig begrepen van wat er in de wereld gaande is' actievoeren (zoals voor Greenpeace) is iets voor kinderen, vertrouwen ' 20 gef' $(60,156,174,187)$. Elk hat vaal Strafhof is hot rece $(60,156,174,187)$. Elk heft vanzellsprekend

(1) Martin Heidegger, Zijn en tijd, vertaald uit het Duits door Mark Wildschut, Nimegen: SUNN, 1998, Lieven De Cauter, De capsularire
beschaving Orer beschaving. Over de stad in het tijdperk van de angst, Rotterdam; NAi
Uitgevers, 2000; Jean Baudrilard, II de schaduw van de zwijgende
meerderheden, vertaald uit het Frans door Ruurd Bakker, Amsterdam:
SUA, 1986. in feite willekeurig op alle stellingen kunnen worden toegepast ('nationalisten zijn zo naïef', 'communiste zijn zo kinderlijk', 'het liberalisme is een jeugdzonde') hebben ze met waarheidsvinding erg weinig te maken. Bijzonder problematisch - voor academicién voo journalisten - is de wijze waarop de auteur gebruik de conclusie telt het boek 233 pain's (inhoudstaf con 6 pasin,s $26,61 \%$ van het hele boek), of 242 (dus o 26 paging 56 hootustukken (33,93\%) wit is vooral prele stelling on bu omat die hoofstrking bevatten. de opwan zijn, Amerika zoude laatste dertigjaar 80 miljard dollar hebben uitgegevenomenissies terng te dringen, er zo 'on if seen sprake was' tond [zijh] dater gif geen sprake was' toen de olietanker Probo Koala afvallosdevor maal interessant en mogelijk, maar oncontroleerbaa che erste hoofds bink verneldignonde melis. teen overweldigende meerderheid van de [Britse] bevolkn het on thementer 'in deonter 'n de ogen wand 's w terechtstat 'schnldig lis zelfs jiclien dat niet wor

Bij controle van de feitelijke claims (al dan niet me voetnoot), blijkt de inhoud ervan in nogal wat gevalen niet overeen te stemmen met wat de auteur ervan makt. Op pagina 24 zegt hij: 'Zo zijn er de afgelopen

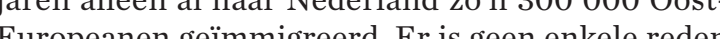
Europeanen geimmigreerd. Er is geen enkele rede

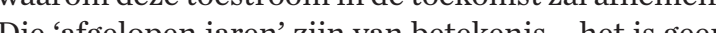
Die 'argelopen jarn' zijn van betekn's - het is geen fenomeen van de 'afgelopen decennia' of de 'afgelopen de toes mar a de toestroom recent heeft plaatsgevonden, versneld, in een relatic korte termijn. Bij controle staat echter in de bron: "Naar schatting zijn er tussen de 286000 effecten brengt arbeidsmigratie ook problemen me efecten zan zake hetche mijn. De 'hetculminatiepunt van een onbepaalde terto andere bron steunt, gaat lijnrecht in tegen de website van de rijksoverheid, die stelt: 'Het kabinet is bezig de valig de grote stroom migranten veroorzaakt. Dan moeten niet tegelijkertijd no

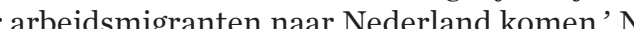
n de auteur twijfelen aan de efficiëntie van de aangekondigde maatregelen - maar niet vermelden dat e aangekondigd worden en in één adem beweren dat enkele reden [is] waarom deze toestroom in de toekomst zal afnemen' is niet helemaal eerlijk. E er is erger. Op pagina 133 schrijft hij: 'Volgens onderzoek komt 70 procent van de gevangenen na vrijlating zou directe, significan zotekn.' ce

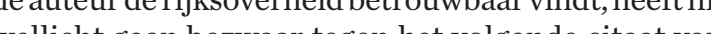
wellicht geen bezwaar tegen het volgende citaat va in 2 jar 'Na trafis 2 jar op in w een stafbar feit. Na een taak( iet

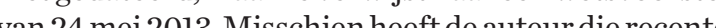
inform nientich 2009 stat te lean: 'van alle volwasenen die in 2006 on stat te leze ' binnen twee jar wa dit $59 \%$. Van de volwassenen die in 2006 traf kregen opgelegd, viel rond de $28 \%$ bi 2006 een [sic jre [sic,jaar] terug in het oude gedrag. In 2004 was dat nog van 3 rijksoverheid zit dus vals on bare cijfers die de auteur a bare cijers die de auteur aur verwijst' zoek dat 8ort war de auteur verwijst naar een onderdat een overgrote meerderheid van de Nederlands dat een overgrote meerderheid van de Nederlandse Alhters link-liberale politick voorkeuren heeft. Baulet (wellicht) verwijt na hetonderzok vat

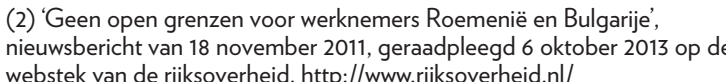
nieuss $/ 201 / 111 / 1 / 2$
bulgariji.hthml.

(3) 'Redicive verminderen', geraadpleegd 6 oktober 2013 op http://www.
rijksoverheid.nl/onderwerpen/recidive/verminderen-recidive.

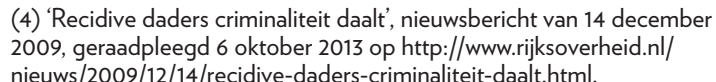


Studiecentrum Rechtspleging, volgens de webstek het eigen opleidingsinstituut van de rechterlijke organi(and

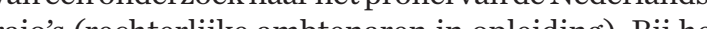

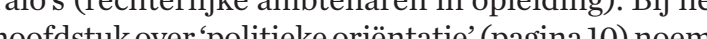
h1\% vau 'p's 2010 D66 de pagna 1) noent $31 \%$ van de raio's in 2010 D 66 de partij van haar voor$17 \%$ PvdA (3\% minder dan de . (n) en dien che (a) geen zittende magistraten. Dat een 'overgrote meer( preferenties zou hebben, bijht dus h

teen standpunt vereist tevens een nauwkeurige analyse van de persoon die het standpunt verdedigt en de organisatie waartoe hij behoort. Die essenticle alweging wordt door de auterin (100-101) Het a (100-101). Hetgaat over een een zeke Bill Warner, de , Conce I slam, die als getuige-deskundige werd opgeroepen jhens hroces Wilders en volgens de auteur deed uitmaakt van 'een brede groep wetenschappers en analistendiealveellanger. wel mag zijn en waruit zijn expertise deskndige dan wel mag zijn en waruit zijn expertise precies bestaat ' n 'weten

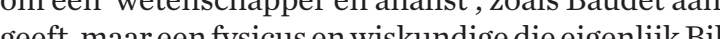
geeft, maar een fysicus en wiskundige die eigenlijk Bill . gens de eigen website als nom de guerre gebruikt.' Naar eigen zeggen heeft Warner "een levenslange interesse Hij publice de nog iijpun ween eren we worden nagegaan nooit in academische tijdschriften, waar de inhoudelijke claims en de wetenschappelijke

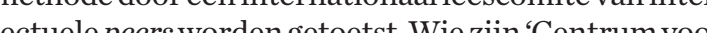
lectuele peers wordengetoetst. Wie zijn 'Centrum voo pet Southern Poverty Law Center, een non-profithet Southern Poverty Law Center, een non-profittie (waaronder hate crime en racisme) bestrijdt en in een aangepast programma tot tolerantie aanzet, is het een for-profit-organisatie, geleid door Warner zelf, die tot de iner circle van de gelti-idloor Warte to che

De wijze waarop Baudet de aangehaalde feiten tot en geïntegreerd model poogt samen te ballen is a even problematisch. De rechtvaardiging van Europa calsificatie toe, is 'even hermetisch als dat van me to marxist, en het laat zich op geen enkele wijze door de these

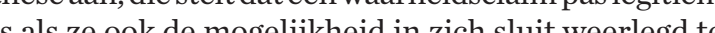
w a worden. Maar hoewel hij vertrouwd is met de stelling, trapt hij in precies die val. Als de natiestaat sterk is (veel bevoegdheden behoud), bewijst dit dat Europa niet goed functioneert, als de natiestaat zwak is (en bewijt ditook dat Europa niet go f f no bewijst dit ook dat Europa niet goed functioneert (de interne contradicties zouden dan het einde van de mant mantellng van de Europese constructie steunt dus op eur terecht Bijwijenappelijk afwijst.

Bijwijlen rijst de vraag of de auteur zich ervan bewust is dat hij de grens tussen de beschrijving en de propaganda overschrijdt. Zo schrijft hij op pagina 174 rist is alleen in natiestaten dat machtige functionarissen kunnen worden onderworpen aan checks-andbalances. 'De term machtige functionarissen' lijkt erg zorgvuldig gekozen. De staat heeft inderdaad bij uitstek jurisdictie over de eigen burgers. Maar heel wat personages die Baudet in de bladzijden ervoor verVladimir Poetin) zijn nar-Bashir, Slobodan Milosevic rissen' Het zijn (sonict zona 'machtige functiona-

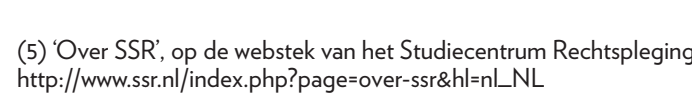

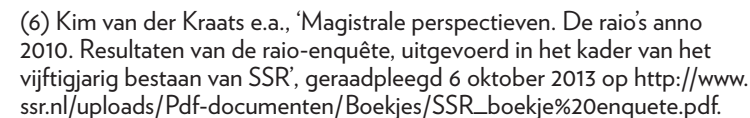
(7) 'Bill Warner', geraadpleegd 6 oktober 2013 op de webstek van het
Center for Political Islam, http://www.politicalislam.com/pages/bio. (8) 'The anti-muslim inner circle', intelligence report, nr. 142 (zomer 2011), geraadpleegd 6 oktober 2013 op de webstek van het Southern Poverty
Law Center httr://www.splcenterorg/get-informed /intelligence-report/
browse-all-issues/2011//summer/the-anti-muslim-inner-circle. als zodanig onschendbaar, en dus niet of nauwelijks onderhevig aan de checks-and-balances. Het is precies door de onmacht van soevereine staten, en onder impuls van het internationale recht, dat de berechtin van staatshoofden sinds kort mogelijk is geworden. Zeggen dat 'machtige functionarissen' in natiestate oncen is nismen is strikt genomen juist, maar dit doen in een ctwat misle Dit geld bijo retorische vraag op perin 173 : 'W retorische vraag op pagina 173: Waarschijnlijk is het VN-vredional Strafhof niet van plan personeel van  ons onschuldige boeren ambach en verwoesten. Dit gebeurde bij verschillende gelegenderde in 1999' ' deerde in 1999.' En Baudet vervolgt: 'Maar het ICC zo dan we rijze heft op die wijze heeft gehandeld, willen vervolgen. Strikt genomen is dit correct. De kans bestaat inderdaad da bom door het ontbrije door het ontbreken van een rechterlijke uitspraak blijft het vermoed het ICC ward de man door het ICC werd aangeklaagd, zonder uit de aanklacht te citeren (de contact sheet van het Joegoslavietribuna heid aan 'angekl deporta heid aan ' politioke, raciale of religieuze grond, on daden/gedwongen transfers, uitroeling, opstiting, foltering, opzettelijk doden, wederrechtelijke gevangenneming, opzettelijk veroonzaken van ernstig lijden') Milosevic even zwa weegt als de ankl tegen ilosevic even zwar weegt als die tegen de NAVO. voldoet niet aan het evenw istoricus wordt verwacht.

En dan zijn er de vele veralgemeningen, die Baudet als goed en noodzakelijk toejuicht. 'Generalseriike is cennis te kom pelijke kennis te komen', stelt de auteur. Toenamevan tieve metho is inderdaed tieve methode is inderdaad een legitieme denkwijze dat de uitsprake die enis te kom - op voorwarde dat de uitspraken die eruit voortvoeien op een stevig empirisch fundament berusten. Zo is de uitspraak ben al meermaals gestolen, bijgevolg zijn alle armen dieven' een onhoudbare, want op te weinig gegeven steunende veralgemening. De vraag rijst op welke [is] het woord van God zelf', bijgevols 'wort Koran [is] het word van God zelf, bijgevolg 'word herinterpretatie en relativering onmogelijk berust. Los van de vaststelling dat nauwkeurig empirisch ing al vanf de eerste eeuwen in de islam aanwez waren", botst Baudets stelling met de ervarin uit war cheser. is (niet'onwarschijnlijk', niet'moeilijk' 'monogelijk

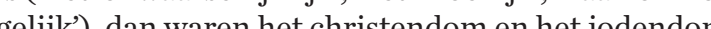
gelijk), dar wang (nim gevangen (niet zo erg lang geleden was immers ook in God bevat dopvatting dat de Bijbel het woord van Goris

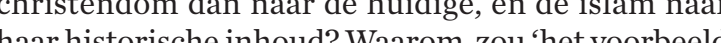

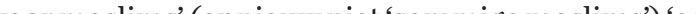
voor moslims' (opnieuw niet 'sommige moslims') 'een oorlogszuchtige dader zijn, en 'de kernfiguur van he christendom [...] een pacifst? Volgens de Bijbel wer Lazarus uit de dood gewekt, an (Jore ove Bedenen ble' het von di gunst verstoken (Johannes XI, 38-44). Is het voor dan een personage dat naar willekeur beslist? Is dat wu en toen? Uiteratron

aard heeft ook Baudet de vrijheid om zich ideeën te vormen en die in geschrifte te laten verschijnen. Vrijheid van meningsuiting is een belangrijk goed, dat door overheden enkelaan bandenkan worden gelegd indien niet werd voldaan aan enkele minimale teltzich. Aandie nornin wetench zich de vraagorde minimale standaard voor sociale wetenschappers het ultieme richtsnoer moet zijn. I Fabian Van Samang

\section{(9) Ellen Lutz \& Caitlin Reiger (red.), Prosecuting heads of state.
Cambridge: Cambridge University Press, 2011.}

(10) De case information sheet (IT-02-54) is beschikbaar op http:///www. icty.org//x/cases/slobodan_milosevic//is/en/cis_milosevic_slobodan_en.
pdf. Wie de aanklachten ten gronde wenst na te kijken verwijis ik graag

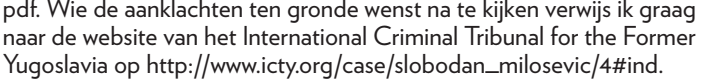
(11) Norman Calder, Studies in early muslim jurisprudence, Oxford:
Oxford University Press, 1993. (12) Vgl. Jonathan Israel, Radicale verlichting. Hoe radicale Nederlandse
denkers het gezicht van onze culturur voorgoed veranderden, Franken, Van Winnen uitgeverij, 2010 


\section{NOUVELLES PERSPECTIVES \\ SUR LA SHOAH}

an Jablonka \& Annette Wieviork

Parijs: Presses universitaires de France, 2013, 128 p.

A ie als onderzoeker de ellenlange literatuurlijsten doorneemt die vaak aan wetenschappelijke studies over de Holocaust zij toegevoegd, bekruipt soms een onbehaaglijk gevoel. Dit gevoel hangt samen met het besef dat een mensende osent essentie van het then eigen te naken. Maar alase wor jaar intensief onderzek het onderi over de Shou wat we in deze tijd, met de ons ter o jus eggen?

an Jablonka en Annette Wieviorka doorprikken met de bundel Nouvelles perspectives sur la Shoah' ce a academische grenzen heeft bereikt. Het boek breng evenartikelensamen waarinvernieuwende inzichten, mod Wat central stat in het boek is immers niet het Wat centran stant in het boek is inmers niet het olocaustonderzoek, maar veeleer het Franse onderzoek naar dat thema. De auteurs zijn in hoofdzaak ransingen , Zjun

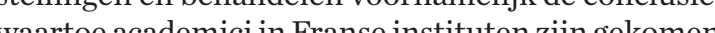
clk land heeftecion ikland heeftechter zijn eigen historie en focust zich daarom op andere deelaspecten van de Shoah - de houding van de Poolse bevolking tegenover Joden èn tegenover de bezettingsmacht roept immers andere ragen op dan de stellingname Led Londen. Ditis niet anders voor Frankrijk, waar de confrontatie methet naziverleden langop zich heeft laten wachten, werd gestivu produres (tegen Papon, Touvier en Barbie) en zich aanvankelijk vooral op de bewegingsvrijheid van he doet hoen doet hoegenaand geen afbreuk aan de kwaliteit van zijn voorondezokes buiten de Fanse londserenzen om nieuwe methoden, nieuwe hypothesen en nieuwe invalshoeken af te tasten

Twee bijdragen zijn erg belangwekkend omdat ze de wordingsgeschiedenis schetsen van grote hoeveelheden samengebalde informatie (zij het als archivalische collectie, zij het als meerdelig naslagwerk) veriscte bruarde ervan bepaalt, maar ook de manier waarop ze ontstonden, . irachtdadige visies. Zo beschrijt Jean-Marc Dreyfu. Duitse Dits die zich bevindt onstond bert ha de Wereldis Werer roolog door het centraliseren van informatie displaced persons. Bovendien ver tienduizenden displaced persons. Bovendien werden persoonsgegeinderen, encen, hast docume worden door Duitsen. Die innor die in het worden door Duitse staatsburgers, die in het kade eisten voor deschade die zungsesez een vergoeding den den geleden. Tevens konden inlichtingen worden ingewonnen over verdwenen of t over verwanten die verplicht in Duitsland waren tewerkgesteld. In 2008, nadat de archieven lange tijd angstvallg voor de buitenwereld waren afgegrendeld, werden de 17 miljoen documenten voor historisch onderzoek vrijgegeven. In een verwant artikel toon tweedelige Enclopedia the Chettos during the in de caust, die op vraged van Yad Vasem tot caust, die op vaag van Yad Vashem tot stand kwam, niet uitsluitend objectieve onderzoeksresultaten invalshoek focu. Zo benadrukken ze vooral de Joodse invalshoek, focussen ze op diverse vormen van verzet, en spitsen ze zich toe op bepaalde regio's, terwijl ze andere (zoals Tran het werk en de redactionel be totstandkoming van het werk en de redactionele keuzes zijn daarom belangrijke factoren om de te raadplegen

Twee artikelen gaan over de specifieke rol van lokale en nationale besturen. Bijzonder interessant is het artikel van Tal Bruttmann over de werking van de plaatselijke administratie onder het Vichyregime. Hij verwijst naar het onderzoek van duizenden omzendbrieven, invulfornulieren, enquêtes en correspondenterla initiatieven werden genomen waarvoor de overkoepelende autoriteiten geen opdracht hadden gegeven. Dit sluit a bij recent oplacht hadde gegen. Diteiten in bit je vitert ben whe [Zie on Hitler's bud a

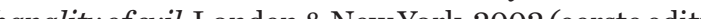
Zürich, 2000)] Som Zurich, 2000). Sommige bureaucraten gingen zo ver on de anti-Joodsebesliten we enonderijndinde uitgaande documenten weer te geven. Op die nanier word duich trije door bijk - een belangijk inzicht dat ongetwijfeld dorfijn of bijgesteld. Audrey Kichord verfijnd of bijgesteld. Audrey Kichelewsky houdt van has kent enkele recente studics tuss rent Zer 'Moissons d'or' [Gouden Poolse socioloog Jan Gross, dat het hofdmon dat het hoofd inhaligheid van Polen was. Kichelewsky waarschuwt vor de . ten met die van Jan Grabowski, die betoogt dat de soltys (de lokale Poolse functionarissen) bij het opspoDuitse dwang en in hun speurtocht nat nit-Joden Duitse dwang, en ij hun speurtocht naar niet-Joden een vergeljkbare ijver ande daglegden (waterop wijs drijfveer was). Dit geeft opnieuw an hoornaamste driffveer was). Dit geeft opnieuw aan hoe omzichtig historici dienen om te springen met veralgemenende uitspraken over de motieven ach ervolging, ove Het ondero Het onderzoek van Nicolas Mariot en Claire Zalc naar de vervolging van de Joodse gemeenschap in het oord-Franse Lens brengt een psychologische en een sociologische invalshoek samen. Het geeft aan hoe iijn, mar iijdence zijn, maar in tijdenvan vervolging tot een openstaand val kunnen uitgroeien. Dit blikk onder meer uit het Frankrijk niet te verlaten toen dit nog mogelijk was. Mariot en Zac stooten op de nog mogelijk was. horde van Ze def horde van de definièring. Welk criterium diende men immers toe te passen om de Joodse gemeenschap te onarm waarmee de onderzoeksgroep werd geselecteerd en de strekken boek en auteurs alvast tot eer.
In een afsluitende ethische reflectie relativeert Ivan Jablonka het Vichy-syndroom waaraan Frankrijk al meer han menteert hij hoe herinnering zeen ziekte is, mere elt Terijl de eerte generatie getuigen verdwijt, 作 doen dit door tegraven in de eigenfamiliegeschiedenis, waordor ze he perijk insnoeren in een keurslijf van historische precice bjectiviteit Dit is een nieuwe trend in de geschiedchrijving die ann met de overlevenden verdwijnt mar kan worden, p de volgende generaties kan worden overgedragen.

Bijdrand in bundels kunnen door hun bedragen. Bung niet de diepgang bereiken die men wel mon in Nouvelles Perspectives sur la Shoah zijn tikgen ren neel, goed geschreven en uitvoerig gedocumenteer Ze behandelen zowel algemene the cestudies die men niet in verselijkbare bun ze ber kelen alvast meer dan de moeite waard. Fabian Van Samang

\section{EXODUS : JODEN OP DE} VLUCHT UIT HET DERDE RIJK

Deborah Dwork \& Robert Jan Van Pelt

Delft: Elmar, 2012, 488 p.

$\mathrm{D}$ boek vertelt het verhaal van de Joden die 1946. Opvallend genturen tussen 1933 iet voor gekozen het relaas van de 'overlevenden't doen, maar schetsen ze in de eerste plaats de verwoeste zijn 'verdronken' of 'verzwolgen' Veel vluchtelinev zijn 'verdronken' of verzwolgen'. Veel vluchtelingen tin antalor de Short zan Pelt raken een wezenlijke dimsievan aan bod komt 
Historici vinden in Exodus waarschijnlijk weinis ieuwe elementen. Maarvoor de modale lezerweten uteurs de belangrijkste punten van deze geschieden te bundelen. Zo geven ze een nauwkeurig overzich van de verschillende maatregelen die de nazi's namen om de Duitse Joden uit het land te verdrijven, voor ze assaal werden uitgemoord tijdens de oorlog. In het Reich waren ze niet meer veilig, maar ook daarbuite stuitten de Joden op onverschilligheid, onmacht en collaboratie. Af en toe kwam er vanuit de bevolking ict to than rrankrijk, de Sovjetunie en Zwitserland. Daarnaas plaatsen de auteurs een aantal heldhaftige figuren in de schijnwerpers, zoals Chiune Sugihara, de Japanse den doorreizen nar Japan Of PaulGrüniger hethoof den dooreizen naar Japan. OrFaul Grünger, hethoof van de politie van Sankt Gallen die vluchtelingen valse papieren bezorgde. Hijwerd hiervoor veroordeeld, uit de politiemacht gezet, en stierf in armoede in 1972 lan dan weer een heus postkantoor, Zodat Duitse Joden op de vlucht in contact konden blijven met hun familie (Gure de secours aur enfants) en van de an het OSE (Euvre de secours aux enfants) en van de zionistische

Degrotegeschiedenis wordtgeillustreerd met persoonlijke en aangrijpende verhalen van slachtoffer - van onbekende, maar ook bekende mensen, zoals

In de eerste jaren, zo blijkt, was Frankije

In de eerste jaren, zo blijkt, was Frankrijk bereid om zelfs de meest armzalige vluchtelingen op te van an. Toch wisten de Joden zich toen nog vrij goed te edeur te veranderen dien kleur te verandering. In an te passen aan hun a Tagascar, in de streek rond Lublin en in het Hoge corden van Rusland weri een. gevoerd om Joden te verdrijven. We volgen de ballingen over heel Europa, onder andere in Zwitserland, tat Het boek toont aan dat de Joodse Duitsers - Joden die zich de nictirniet als een ninderheid beschourden niet inzagen dat ze een beroep konden doen op interna-

De passages over de Joden in Franse internerings- kampen zijn onthutsend. We lezen hartverscheurende erhalen van families die uiteenvallen. De kinderen van erhalen van families die uiteenvallen. De kinderenvan

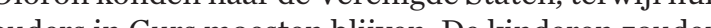
ouders in Gurs moesten bijven. De kinderen zouden vant Marseille afreizen maar zagen hun kansen op (a) lijk vielen ze in handen van de Duitsers.

Het boek stopt niet aan het einde van de oorlog. I 1946 zaten Joden achter prikkeldraad. Diegenen

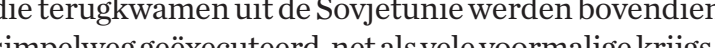

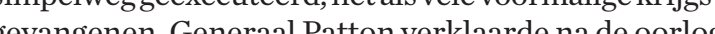
ceorlog en'.Zijn collega Eisenhower en ook president Truman In

作 作 de hetbijzon tor pen te 0 jaar lang hun huis was geweest

Het boek is chronologisch opgebouwd en bestaat it vier delen, die telkens vijf thematische hoofdstukken bevatten: feitelijk materiaal en data, mensen, plaatsen, papieren (paspoorten, visums, brieven, lijsten ctrijke historishe fotos zijn. Dekaarten en voora verhelderen de teks op verschillen punte verhelderen de tekst op verschillende punten en zijn vorzich ien edereen die geinteresseerd is in deze geschiedenis, en zeker niet alleen tot specialisten. Ondat het zo helder sescheed van bijzond a pert van het inmen iszonder aspect van hoden is aangedaan door het nazibeleid, maar ook door de was van het drama.

$$
\begin{array}{r}
\text { Jean-François Forges } \\
\text { (Vertaling: Anneleen Spiessens) }
\end{array}
$$

-$$
\bullet
$$

SOLDATEN. OVER VECHTEN,

DODEN EN STERVEN

Sönke Neitzel \& Harald Welzer, vertaald uit het Duits door René van Veen, Marten de Vries \& Marcel Misset Amsterdam: Ambo, [2011] 2012.

oen dit boek van historicus Neitzel en psychooen dit boek van historicus Neitzel en psycho-
socioloog Welzer in 2011 in Duitsland verscheen, socioloog Welzer in 2011 in Duitsland verscheen,
deed het behoorlijk wat stof opwaaien. Voor wie meer wil weten over de Tweede Wereldoorlog (die niet wordt vermeld in de titel) en de Shoah, is het in elk geval een aanrader, al zijn de conclusies van de studie voor discussie vatbaa:

Aan de basis van het onderzoek ligt een zogenoemde "gelukstreffer", die uiteraard niet helemaal op puur toeval berust. In 2001 doet professor Neitzel in de archieven van Groot-Brittannie een unieke vondst hij dukelt verslagen op van clandestien afgeluisterde gesprekkentussen Duitsekrijgsgevangenen-soldaten pen. pen. How Hier werd de praktijk asprake ' is hustriël alle tijden. rer werd de praktijkechterop in gepast. De historicus werd naar eigen zeggen 'als het ware de or in

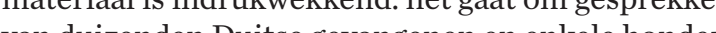
van duizenden Duitsegevangnen en enkele honde den Italianen.

Later stuit Neitzel in de Amerikaanse archieven op een vergelijkbare verzameling documenten, tweema zogrouls de Britse. In total ind hijbijna 150000

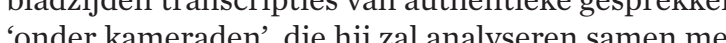
onder kameraden', die hij zal analyseren samen met zijn beroende collega van de Universiteit van Gieße Harald Welzer: We genennie wer. We ky spraken. Het resultaat is een rijk verslag van ongevee 600 bladzijden. In hoikstur' trens trachten zoderije van het hele van het hele boek, geeft in een vijttigtal rubrieken een overzicht van de gespreksonderwerpen die de gevangenen aansneden, op een monot zij niet meer van wen hun hart luchtten bij hun kameraden. Zo vertel- len ze elkaar hoezeer ze zich hebben vermaakt: piloten mochten burgers op de vlucht neermaaien met mitraileurs, en wie aan boord was van een onderzeeër moch andere boten tot zinken brengen. Maar de gevangenen praten ook over de 'uitroeiing', over Stalingrad, over de Führer en de Waffen SS, en ze spreken hun angst uit voor wat hen na de oorlog te wachten staat.

De conclusie van de analyse is echter betwistbaar. ezers raken makkelijk gefascineerd door het verhaal, the rechtstre ks geconfronteerd worden met de gruwel. Zonder terughou Zonder ter tor

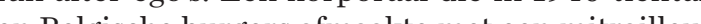
te het Russische front vochten, beschrijven vor Wanner deze 'oogetuigen' hat henben ove

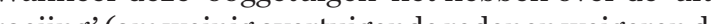
roeiing' (om weinig overtuigende redenen weigeren de wordt het bijna and raglijk om verder te lezen. ijin deze bijna ondraaglijk on verder te lezen. Toch

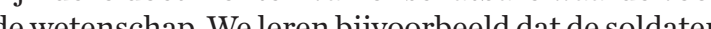
zun een premie opstreken wanneer ze opdrachten tot ee over ' bieden in het uitroeiing donten die een dieper inzich cen con berhtelijk kader, weten Neitzel en Welzer eenuiters belangrijke bijdrage te leveren tot het onderzoek in sold Joldaten op de hoogte waren van de uitroeiing van de Joden in het gebied dat Timothy Snyder bloodlands noemt. We mogen niet vergeten dat tussen 1939 en toerd Den 'deel uitman 'del in vinakel vatere ol in veel grotere mate dan recente studies over het alles op de hoente, zo tellen $z e$ mar de gen was van alles op de hoogte, zo stellen ze, maar de gesprekken ten wisten blijkbar dat er gebruik werd ten wisten blijkbaar dat er gebruik werd gemaakt van lich lichamen werden opgegraven en verbrand. Omdat er bovendien zo veelgeruchten de ronde deden, gaan de auteurs ervan uit dat zo goed als iedereen wist dat de Jodenw 
schuitje zitten - dat de Duitse soldaten zich bijzonder kritisch uitlaten over de gruwelijke behandeling van de gevangenen van het Rode Leger.

De oproep van de auteurs om het debat te 'ontdeologiseren' overtuigt echter niet. Dat standpun wordt vandaag de dag wel vaker verkondigd. Hoewe auteurs de populaire hypothese van de 'b beunen de auteurs de populaire hypothese van de 'banalisering an het kwaad met iets te veel enthousiasme. Het gedrag van de nazi's tijdens de oorlog lijken ze te willenter 'preter vande antropologisering van het oorlogsgeweld.Voo e rection caur lo 'C'́tait pendant la guerre - Et après?' [Da fabula.org. "Cétait pendant la guerre - Et apres? " DDat was tijdens de oorlog. En daarna?.. De auteurs willen zond zundigonderzenten Poveren. Ondat Himmler tijdens zijh toespraak in Posen de uitroeing an de Joden slechts sporadisch vermeldt, besluiten de auteurs dat dit project niet de priteit was van de soldaten of van de SS. Even later stuiten we op een ongelukkige formulering: de auteurs Sho [de term kom amper voor] mat de oog Shoah [de term komt amper voor] maar de oorlog de peste slachtoffers nalkte. Als nen zich dan in het persectiefvande soldaten plaatst, zo gaan de auteurs cite ' ' nooit een 'uitroeingsoorlog', or rassenoorlog hebben gevoerd. In hun eigen ogen' dus - dat is werkelijk ce en we Wrmacht of de Waffen SS, en de lotaten le Finsatzon de Linsatzgruppen die Joden in groten getale hebben,

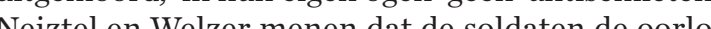

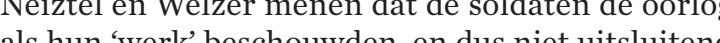
handelden uit ideologische overtuiging. Het grootste probleem is dat de auteurs de voorkeur. Hever grootste probleem is dat de auteurs de voorkeur geven aan een ociopsychologische aanpak in plaats van een historsche. Nergens geven ze een definitie van het sleutelbegrip 'partizanen', waar de Duitsers nochtans naa in Westrest-Europa (Oradour, de Adreatijnse grotten) te con zogenaamd partizanen'. Het boek lijkt op dit vlak niet verder te bouwen op het werk van Hannes Heer en zijn team in de jaren negentig, en hun reizende tentoonnog, Heer wordt niet eens vermeld in de bibliografie.
De auteurs reppen bovendien met geen woord over de jaren 1933-1939 en de ideologische conditionering van de manschappen, die heeft gemaakt dat veel soldaten iteindelijk oorlogsmisdadigers en génocidaires zijn geworden. Alles welbeschouwd kunnen we echter niet ditbok heen. Het is een uitert betangijk dit boek heen. Het is een uiterst belangrijk werk, There hzelf en over un daden.

$$
\begin{array}{r}
\text { Robert Kahn } \\
\text { (Vertaling: Anneleen Spiessens) }
\end{array}
$$

\section{LA SHOAH. THÉÂTRE ET CINÉMA AUX LIMITES DE LA REPRÉSENTATION}

Alain Kleinberger \& Philippe Mesnard (red.) Parijs: Kimé, 2013, 543 p. zinspelen op het verbod op representatie t gaat namelijk over limites, grenzen die we ons afvragen hoe legitiem dat eigenlijk is, en hoe ver we hierin kunnen gaan. Omer Bartov legt de vinge op de wonde en verwijst naar het dilemma in het bijzonder controversiele Don't touch my holocaust van sher flalim (1994). Volgens Bartov demonstreert de film iijke gruwelijke herinnering vandaag de dag, en toont hij rerleden vithen de hedendaagse identiteit en het bewustzijn valkuilenzien te vermijden: valkulenziente vernijden.enerzijds een verlammend gevoel van ontzetting omwille van dit vreselijke verleden, en anderzijds een bedrieglijke gemoedsrust die het verdringen van dat verleden oplevert. Kunst kan en uitweg bieden.

Dit vormt precies het uitgangspunt van de bundel van redacteurs Alain Kleinberg en Philippe Mesnard, waarin een breed gamma van 'representaties' en de daaraan verbonden vraagstukken aan bod komen Wanneer is men films beginnen maken over de ver- werden die films ontvangen? Om wat voor films gaat het (documentaire, fictie, en alles daartussen)? Hoe vind je een evenwicht tussen overdrijving en undertatement? Dit zijn slechts enkele van de vele vragen die in het boek worden gesteld.

Alle auteurs stellen vast dat er steeds meer ficti verschijnt over de Shoah, en eerder in film dan in the Toch is het gen re theater. Toch is het geen recent fenomeen. de eerste fins over de Shoah verschen al meteen na de ooro. Arisch She generatie. Les Illegaux van Meyer Levin (1947). Deze mentis erst nog voor het Eichmann-proces in 1961. Dat is opmer-

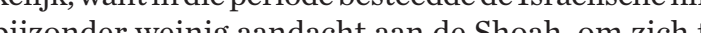
bijzonder weing aandacht aan de Shoah, om zich te concentreren op de Sabres. Hoewel Levins film wel

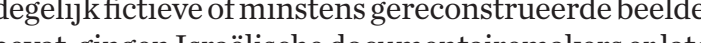
bevat, gingen Istaelischedocums op voortbouwen en integreerden zepaalde scènes

Alain Kleinberger maakt een analyse van Wand Jakubowska's La Dernière Étape (1947-1948). Als conBirkenuterect Ze da in Birkenau terecht. Ze draaide haar film dan ook in Bir figureren. Uit verschillende hoeken kwam kritiek: den zou het verzetverherlijken en de aandacht afleiJonverid Joods was. Kleinberger oordeelt echter dat de film op dat vlak niet dubbelzinnig is. Het probleem situeert fers retros. na dief bor wound films itd DDR $z$ s. Ster eenduidig: Die Mörder sind unter uns van Wolfgang is Duitsland de sear is Duitsland dan precies schuldig aan? Enkele van de Shoah werd over Joods-Duitse geschiedenis en de Shoahwerdengedraaidn Baber ste centrum an film, technologie, artistieke bedrijvi heid en slechte gewetens'.

Aan Franse zijde buigt Antoine de Baecque zich over een complex onderwerp, namelijk de houding van Jean-Luc Godard tegenover de Shoah. Godard weigert elke vorm van esthetiek, en kiest resoluut voor een precieze montage 'die in het verschil de uitroeiing met ziju.Zijn milltantine brengthem in 1969-1970 met zijn cas ing in Histoire(s) du cinéma confronteert hij de filmwereld met har collectieve onmacht in woelige periodes. Hij acht zichzelf medeplichtig, omdat hij niet heeft kunnen vermijden 'dat Spielberg Auschwitz heeft gereconstrueerd'. Terwijl Lanzmann weigert om archiefmatercestruk eamighe Tet is dids alleen op politiek vak de auteurs Het is dus niet alleen op politiek wak dat de auteurs van Shoahen Notremusique tegengestelden zijn. Mee

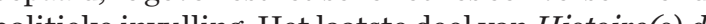
ciném chón . pémy hanzmann typert als 'fictie van de werkelikh.

De viag van Godard en Laneman dult op in

De vraag van Godard en Lanzmann duikt op in cowat alle teksten van de bundel en verwijst naar het Om het met de woorden van Jean-Michel Frodon te Om het met de woorden van Jean-Michel Frodon te egent wat is de filmische norm om een nooit geziene gebenrtenis weer tegeven? Er zijh zoveelverschillende mogelijkheden, en evenveel vragen waarop eerst ee tret treden, trac

Eerste vraag: is de documentaire een neutraa document? In haar analyse van Theresienstadt ontleedt Luba Jurgenson de propagandastrategie achte - film die de gevangenen maakten in opdracht van de (Primo Levi) waarbinnen de Sonderkommando ziche' (Primo Levi) warbinnen de Sonderkommandos zich in beeld In fictie worden deze mensen vaak negatief in beeld gebracht, en staan ze lijnrecht tegenover de hecker van de gewapende strijd en het verzet. Annette eckar er Yannicer een historisch personare wordt 'gefictier wanneer een historisch personage wordt 'gefictihet Poore ve het Poolse verzet, zo stelt Becker vast, werd getrans(on Joodse ramp; hij Jord hechtvacrige onder de Naties en nagenoeghalve altijd 'objectiever' is dan fictie, mar evenzer berust altijd 'objectiever' is dan fictie, mas evenzer p esthetische en politieke keuzes.

Een tweede krachtlijn in de bundel is die van de nationale vervormingen'. Uit de studie van Matthias 
Shoah transponeren of omkeren, om zo de Duitsers als lachtoffers op te voeren: het der die ars be tevoer (2)

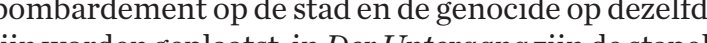
lijn worden geplaatst, in Der Untergang zijn de stapels jken in het Lager die van Duitse soldaten. De overcen maserom Hetis nieto Hetis nietondatso\% vallow gered, zo betoogt Millicent Marcus, dat Italie haar ro De rassenusten Deras van film, die nochtans erg social geëngageed is, heeft ilm, die nochtans erg sociaal geengageerd is, heeft cich pas lat over dat onderwerp gebog. De auteur. hast de a de Sovetuij en de ontbinding van de communistische partij hebben de weg vilj gemaakt voor een ne dwong delianen bovendien on de viag te stellen wong de Italianen bovendien om de vraag te stellen

rankrijk lange tijd om het onderwerp heen gedraaid. (Ten minste als we Nuit et brouillard buiten beschouwinglaten; meerdere auteurs erwijzen nar deze flu char ring vormde.) Pas na Le Chagrinet la pitié uit 1971 gaa In je joren 70 verschijn In de jaren 70 verschijnen onder andere Les Guichets du Lounre, Lacombe Lucien, maar ook Monsieur Klein van Joseph Losey. In haar artikel wijst Anny Dayan

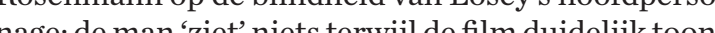
hoe de razzia van de Vel d'Hiv wordt voorbereid.

De Hongaarse film, en meer bepaald $\hat{E}$ tre sans destin, staat centraal in de tekst van Catherine Coquio. De film is gebaseerd op het gelijknamige boek van Imre Kertesz en werd geproduceerd in samenwe king met de auteur. De slechte ontvangst van de film cot de . Cathe coquio platst de flim in het lichtvan de geschiedenis van het genre en ontwaart een 'culverschillende land in de wisselende receptie in vinden we tanden. Dat internationale perspectie Bartov “Le "Juif” au ciném Bartov, Le Juif au cinema: du Golem a Don't touch my Amerika, Polen en Israël. In zijn analyse van Daniel
Wachsmanns Hamsin (Israël,1982) geeft de auteur aan hoe stereotiepe beelden van Joden en Arabieren elkaar p een complexe en paradoxale manier doorkruisen.

Een derde rode draad in de bundel is de artistieke tilering. Magali Chiappone-Lucchesi stelt een studie voor van Der Stellvertreter van Rolf Hochhuth en de verfilming door Costa-Gavras, Amen. Er wordt in beide gevallen gekozen voor een vijj realistische ensceneran heewel het toneelstuk duidelijk op de grenzen van het genre balanceert: de regssseur maakt gebruil vanaijzinte cocun aanwijzingen en stapt zelf de scène op - eén voor eén the theater. Hettoneelstuk en de filn richten zich bovendien 3 iij 1963 ijn nier dezente heeft met zijn werk bijgedragen to

De twee andere artikels over theater behandelen stukken waarin niet meteen wordt gestreefd naar een getrouwerepresentatie, zoals het werk van Sarah Kane over trauna (Elisabeth Angel-Perez) of het 'poppenDe De acteurs van Hotel Modern spelen met poppetjes in een maquette en maken zich op die manier de psychologische mechanismes eigen die aan de basis liggen van de werking van het kamp. de positiewissels en de talu deling zodat de handelingelke morele betekenis verliest. Daa te te ontwikkelen moeten we volgens Walter Benjamin sele geschiedenis. Het spel, en niet de identificatie selegeschiedenis. Het spel, enniet de identificatie met

Alle artikelen stellen impliciet of expliciet
ale Alle artikelen stellen impliciet of expliciet de vraag naar de ontvangst, en dus onrechtstreeks naar de intentie van de auteur. Hoewel de auteur-regisseu

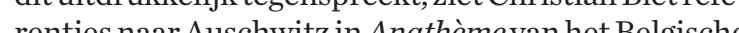
renties naar Auschwitz in Anathème van het Belgische theatergezelschap Groupov (Avignon, 2005). In Philip Roths Nemesis lest hij dan weer een allegorie van het kanp, Zoals LaPestedatwas. In beide gevallenweet hij de lezer van zijn 'visie' te overtuigen, en blijkt dat de auteursintentie-cenconcept waar de literatuurkritiek lang geleden afstand van nam, maar dat klaarblijkelijk een wederoptreden maakt - slechts een van de vele parameters is waaraan een werk haar betekenis ontdeelvanhetpublikhetniteensismetdenten groot. van de auteur. De film La Question humaine van Nicola Klotz (2007) is zo'n geval. De film, naar de gelijkna. gebaseerd op Zygmunt Baumans Modernity and the Holocaust en legt een verband tussen het tijdperk van het nazisme en dat van het hedendaagse kapitalisme. Stephane Bou haalt enkele markante uitspraken aan Niemand durft te zeggen dat de taal van de MEDE (Mouvement des entreprises de France) sterk lijkt op de Amtsprache van Adelf Eichnann' (Enzo Traverso), of 'De organisatie van de Holocaust kan zo in een handboek voor wetenschapsbeleid' (Zygmunt Bauman). De film zorgde voor behoorlijk wat controverse, maar heef we de aandacht kun we ro het grootkapital in de opkonst van het nazisme. De

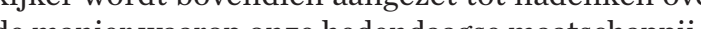
e matschappij is

Ook La vita è bella van Benigni is een film die vee stof deed opwaaien. De ludieke en dromerige ensceneing an de kannen kon een antal kjkers niet bekoren. In de marge van haar analyse van Tarantino's de film van Benigni en Train de vie van Mihaina de flm van Benigni en Train de vie van Mihailean. belozte in van houden 'een utopische en messiaanse en en die parallelloopt met de tragische kennis van wat Tarest. Alternatieve representaties zoals de gore van intende het is juist omdat het publik het

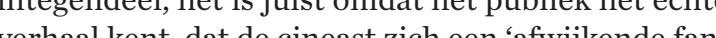
verial kent, dat de cinst zich een 'afwijkende fanlijkheid versterkt lijkheid versterkt en tegelijkertijd alternatieve versies suggereert. Ik sluit af met deze mooie uitspraak die ans als een ruintevan

Anne Roche
(Vertaling: Anneleen Spiessens)

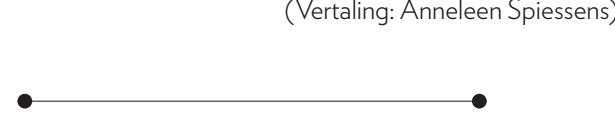

\section{ABUSI DI MEMORIA}

Valentina Pisanty

Milaan: Bruno Mondadori, 2012, 152 p.

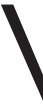

eertien jaar na de publicatie van een reeks wersen racisme in Italië, buigt Valet antisemitiche zich over de historische ontkenning en psychische ties dinging van de Joodse genocide, en de implica-

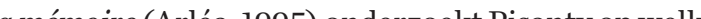

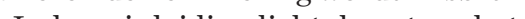

n haar inleiding licht de auteur het verband toe iijen heringering en geschiedenis - een verband dat cher 'misbruikvan herinnering' 'misbruikvan de herinnering: negatie, sacralisatie en deld in hun onderlinge samenhang de drie vormen vanruk bruik pasen in elkar als puzzelstukken, zo geft ze (an aan, en zijn intrinsiek met elkaar verbonden. De protagonisten van de verschillend De allijd van bewust.

De collectieve herinnering (niet alleen in Italië, overigens) kwam tot stand na veel getouwtrek, belandencen correcte visie op desinn de herinnering vaak zo oppervlakkigis gebleven (alleszencer sch werd onderzoch

Pisanty geeft een overzicht van de drie belangrijkste vormen van misbruik en de manier waarop die stapswijst echter amper nimte veroverden. De auteur verelk van deze stromingen heeft uitgelokt (bijvoorbeeld bij Primo Levi die nochtans wordt ver (bij), of bij Primo Levi die nochtans wordt vernoemd), of naa chier enche op negationistische, sacraliserende en banaliserende op negationistische, sacraliserende en banaliserende niet, die aanleiding gaven tot vernieuwende studies overde aanking such onderzoek op de sites van de genocide. 
Het boekvan Valentina Pisanty is daarom niet meer dan een handig vulgariserend instrument. In tegenniet meteen fundamenten voor verd legt de auteur zoek. 1 Frediano Sessi
(Vertaling: Anneleen Spiessens)

\section{MEIN KAMPF}

\section{HISTOIRE D'U'N LIVRE}

Antoine Vitkin

Parijs: Flammarion, 2013, 332 p.

e studie van Antoine Vitkine is bijzonder or gineel, in het bijzonder omdat de auteur focust gineel, in het bijzonder omdat de auteur focust
op het boek Mein Kampf als dusdanig. Hij deert de geschiedenis van de publicatie en dien ontvangst in Duitsland en daarbuiten, vroeger en $\mathrm{nu}$ Daarvoor grijpt de auteur terug naar de figuur van Hitler als 'schrijver', schetst hij de opkomst van het

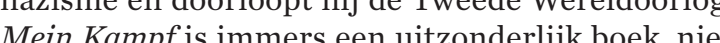
Mein Kamp $f$ is immers een uitzonderlijk boek, nie alleen onwille van de stellingen die erin worden verche in die tijd heersten) maar ook en vooral omwille va impact die het heeft gehad.

Vitkine bestudeert eerst de verkoopcijfers van het boek en de ontvangst in Duitsland. Buiten de VölkischGeveging wordt Mein Kamp in 1925 lauw onthaald Geen enkele groepering of partijlijkt het belangvan de publicatie in te schatten: niet de communistische partij, niet de Kerk, (t) miljonan ilinoen Duitsers het boek. Burgemeesters overhandigen het aan pasgen witse bedrijven prijzen htische partij, het leger en de Duitse bedrijven prijzen het aan en schenken het aan klanten of sympathisanten. Aanind indoctrinatie van de jeugd, worden prentenboeken gedrukt met citaten uit Mein Kampf en verhalen ove

Andere landen gaan na 1933 over tot de vertalin van het boek, maar censureren passages over buiten- landse politiek. 'Als ik in 1924 had geweten dat ik ooit kanselier zou worden, had ik Mein Kampf nooit geschreven', zou Hitler een vriend hebben toevertrouwd. Uit de tekst komt duidelijk zijn expansiedran maar voren, en dat kan problemen opleveren zolang de ith Hitler wildar landen beperken. Sonnge uitgevers, onder andere in de Verenigde Staten en Groot-Brittannië,gaan akkoor met het voorstel van de Duitse uitgeve

In 1933 telt het Italië van Mussolini een gigantische som neer voor de vertaalrechten. Omdat de vertaler, Angelo Treves, Jood is, verwijdert de uitgever, Bompiani, diens naam van de kaft. Het is niet duidelijk wat de bedoeling is van de uitgever: wil hij de Italianen waarschuwen voor het nakende gevaar, of wil hij hen indoctrineren? Ook in Frankrijk zijn de uitgever moeilijk in te schatten.

Frankrijk wordt zwaar onder vuur genomen in Mein Kampf. Hitler wil de Fransen daarom geruststellen en toont zich tijdens een interview met Fernand de Brinon (toekomstig collaborateur) in november 1933 van zijn vredelievendste kant. Hij minimaliseert Mein Kampf, dat hij afdoet als 'een boek vol verwensingen dat ik schreef in de gevangenis'. Hij slaat ook het aanlatines, die het werk wil vertal Noun is Élitions lathes, die het werk wil vertalen. Sorlot is een merkwaardig figuur, die zich aangetrokkenvoelt tot het fascisme en zich later zal aansluiten bij de Parti franciste van MarcelBucard. Handelthij vanuit conmercièle of politieke motieven? Hik besluit de afwijzing van Hitle te negeren en het boek toch te vertalen. Daarbij krijg Oud-strijders ${ }^{1}$ zijh contacten bij het ministerie van Oud-strijders maar ook van de LICA (Ligue internationale contre lantisemitisme, voorloper van LICRA) verkoop. De tekst komt terecht bij paent in voorverkoop. De tekst komt terecht bij parlementairen, Calmettes, verlathierover 'Solothefteen (1) Vitkine rekent in de marge ook af met een hardnekkige legende. "Elke
Fransman moet dit boek gelezen hebben', is eer vaak aangehaalde
uitspraak van Lyautey die verscheen op de kaft van een aantal uitgaven uitspraak van Lyautey die verscheen op de kaft van een aantal uitgaven.
De Confédération des contribuables [Confederatie van belastingbetalers].

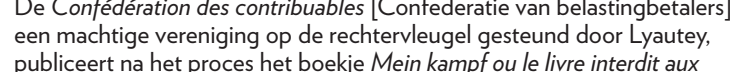

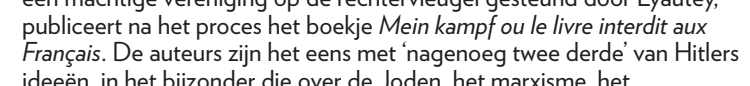

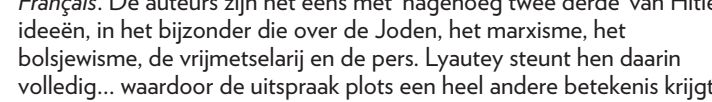

aantal exemplaren opgestuurd naar de leden van het parlement. Onze afgevaardigden hebben geen tijd on e boeken te lezen die in massale hoevee boekhandelaars in de etalage liggen.' [onuitgegeven getuigenis in privésfeer]

Fitler dient een klacht in en heeft de Société des gens de lettres an zijn zijde. Tijdens het proces van Jert iin, voo aijn, vooral mar het publicatieverbodkontinalle ence not et fors ins gaar hij heeft i chzelf belocijk Maar hij heeft zichell de auteursechten van de Franse schrijvers wel hoog in het vaandel dragen als hij hun werken verbiedt

Het argument houdt steek, ook al is Sorlot allesbehalve antinazi. Hij zal later werken uitgeven die Pétai en de collaboratie goedpraten, maar gaat tegelijkertij door metde landestiene verkoopvanin Kein Kamp. Da latsteknt wordt D'Astier de la Vigerie getuigt daing hij zijn plicht. als Fransman heeft vervuld: hij lan dat hij zijn plicht als Hrans zo cruciale informatie' zo cruciale informatie.

Hoe interpreteerden de Fransen het boek dan, of ze nu de integrale of gecensureerde versie lazen? Vandolitici geloofden dat het een soort ‘jeugd stuitend. Politici geloofden dat het een soort jeugdboek van hitler was; volgens het leger was Hitlers project een de Pruisische dat wast Sommigen geloofde de Pruisische machtslust. Sommigen geloofden dat de auteur het vooral op de communisten en de Sovjetunie has gent, en zagen daar geen proble in warsch Trotski vanuit ballingschap in Frankrijk voor de gevaren van Hitl zijn krant De Waarheid, die zogenaamde pacifst in zijn krant De Waarheid, die vooral door militanten wordt gelezen. Ook Cachin slaat La Revue littéraire mer zij viner 1934, en Suarès

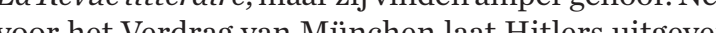
voor het Va Doctrine publiceren bij Fayard, Eher-Verlag Ma Doctrine publiceren bij Fayard, een soort 'geautoriseerde versie van Mein Kampf van de de ene werkt voor Candide, de andere voor Je suis partout. De tekst bevat nog steeds antisemitische stellingen maar werd grondig gekuist om minder agressief over te komen tegenover Frankrijk. Twee maanden $n$ München, op 6 december, sluiten Frankrijk en Duitsand een vriendschaps- en samenwerkingsverbond.

Wanneer de oorlog uitbreekt, groeit de vraag naa ien Kampf. in meil n ans en analyses. Sommige zijn geschreven om de lezer te wars We

Tijdens het proces van Neurenberg v

Tijdens het proces van Neurenberg wordt $M e i n$ Kampf als belastend bewijsmateriaal aangevoerd. jor cen, zeker omdat vanaf 1945 systematisch feiten gen, zeker omdat vanaf 1945 systematisch teiten en a Meine Zeit: Kurt Habritter et la déner ' mémoire 112, 2012 64 77] Dat verkl ent gistoire warom $113,2012,6477$. Dat verk is werkelijke verspreiding en ontvangst van het boek Toch hofden de mensen . We zagen at dat r meel We zagen al dat er veel samenvattingen circuleerden, zo bek de publeke opinie hebben ingewerkt. Uiteraard we debasis ligtvan de vernietiging van de Europese Jod Maar het heeft wel bijger Maar het heeft wel bijgedragen tot de banalisering an de late genaakt (Jean-Pierre Faye). Vitkine wijst bovendien het regime mogen dan wel terechtgesteld zijn in Neuretrerg vele anderen hebben zich uit de slag kunnrenberg, vele anderen hebben zich uit de slag kunnen leider of politicus. Zo schreef Globke, de statssecreleider of politicus. Zo schreef Globke, de staatssecre.

Tot slot bestudeert de auteur de ontvangst van het boek na de oorlog in het buitenland. Omdat Hitle het auwoner van Beieren was, beheert die deelstaat het auteursrecht. De verspreiding van het boek word imago van Duitsland niet verder te schaden. De situatie 
op het terrein is echter niet evident.

In sommige landen is Mein Kampf verboden, althans in theorie. De deelstaat Beieren wordt regelnatig aangesproken door Duitse ambassades in het uitenland om het boek uit de rekken te halen. Dat gebeurde al in Rusland, Portugal, Tsjechië, Polen e Turkije. Toch blijft het boek circuleren. In Ruslan wernde Mein Karnf
kringen.

In een aantal andere landen, zoals Italië, de VS en Engeland, is de aankoop van het boek legaal. Ook in enkrijk is dat zo, hoewel niet iedereen daarvan op de hoogte is. Na zijn rehabilitatie in 1948 geeft Sorlot extreenrechtse, soms negationistische (Rassinier) tekent Eerst doet hij dat discreet, vanaf 1960 openlijk. Na ee Darquier de Pellepoix onderneen de LICRA in 1978 Dari gerechtelijke stappen om Mein Kampf te verbieden, cen cerd. De rechtbank gaat hier niet in mee, maar eist de 2016 zal een hitische uitgave verschijer bij Fayard.

In Duitsland blijft het boek verboden, behalve voor bepaalde onderzoekers en historici. Alleen passages voorzien van een wetenschappelijk commentaa 列 2015 gaat het boek deel uitmaken van het publiek domein en publiceer Münct

Buiten Europ 'war de historische ervaring

Buiten Europa, waar de historische ervaring geen oriction . in Indië, Azië, Fran in wereld. In de jaren 30 delen het Arabisch nationalisme den: Engeland, Frankrijk en de Joden De Protoconden. Engeland, Frankrijk en de Joden. De Protocollen an de wijzen van Zion zijn ontegensprekelijk een best

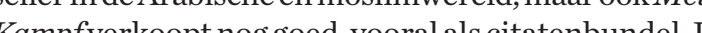
Tampije erkoopt noggoed, vooral als citatenbundel. In The dat weing mensen het boek effectief hebben gelezen, maar dat ze er wel vaagwegnaar verwijzen om het conzijn werk in bescheiden termen: 'Het is geen echt geschiedkundig boek, maar eerder een boek van een journalist die historicus probeert te zijn.' Hij gebruikt (in het bijzonder de

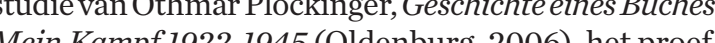
Mrift Kamp 1922-1945 (Oldenburg, 2006), het proef. Bordat. Vithe maakt dat onderzoek toegankelijk voring het pebat ove het publicatieverbod: we moeten Mein Kampf niet verbieden, meent hij, maar ontcijferen, en de historische 列 cerchis ich niet letterlijk herhaalt, we mogen van de jaren 30 geen absoluut referentiekader maken maar moeten hoef ik daar niet aan toe te voegen.

$$
\begin{array}{r}
\text { Anne Roche } \\
\text { (Vertaling: Anneleen Spiessens) }
\end{array}
$$

\section{MONSIEUR OPTIMISTE}

Alain Berenboom

Brussel \& Parijs: Genèse Édition, 2013, 236 p.

lain Berenboom (1947), de bekende Franstalige Belgische auteur, advocaat, specialist van auteursrecht en professor aan de ULB, is in he ederlandse taalgebied slechts toegankelijk via drie (1996) dis vertandse meiden (1996), de vertaling die Ernst van Altena maakte van $L e$ pique-nique des Hollandaises uit Aly kn we nog over twee verhalen, Ketjes, broekschaaiter (n) cront 'Bon doontjespen (2003) tergelegenheid van de $75^{\circ}$ verjaarhalen is van de hand van de recensente die ook instond hoor de vande hand vande recensente die ookinstond oor de vertaalde fragmenten uit Monsieur Optimiste. Met Monsieur Optimiste levert de Brusselaar zijn elfde roman af, en net als in zijn andere werk Le lion d'or (2000), La Jérusalem captive (1997), of zijn met prij-
zen overladen Le roi du Congo (2010), weethij ook (20) benaderen. Maar er is meer aan de hand. Al in het verhaal 'La fille du super 8' uit 2003 gaat een verteller n la de che in een kast had bewaard. Hij herkent niemand op het

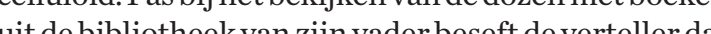
hij hij nagenoeg niets van het leven van zijh vader wist, ch a de grootvach echte detective gaat hij op onderzoek uit in de Joodse gemeenschap an Brussel. Mar Berenboomlaat in dit con 2013 won, duil vel dier in het verleden van iij deze zoektocht met zijn eigen identiteit. hij deze zoekt

Aanleiding voor het schrijven van deze biografie van zijnouders is de doodvandevader wande verteller Net in 'La flle du super 8 ' wet de verteller, ct als in 'L nalle du sur in het verha hats van zijn ouders. Maar anders dan

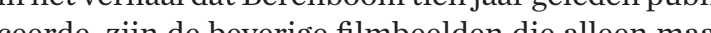
ceerde, zijn de beverige filmbeelden die alleen maar ch tö rële documenten en brieven die weld gen door redledocunter ets onthullen over het leven van ziln ouders. Beiden ingrijpen van ingrijpen van een Belgedesonche.. Berenboom roept bie elo Als je ove de herk

Als je over de herkonst van de ouders leest bef je migranten was die eind jeel de achtergrond van de migranten was die eind jaren twintig in Brusse

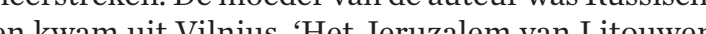
dat in zijn geschiedenis steeds van sat Litouwe dat in zijn geschiedenis steeds van statuut en landsPolen en werd in 1939 door de Sovjets bezet 'Mijn Polen en werd in 193 Rusisch, zij lerde metkunde in het Pools Russisch, zijlecte meetion in het Litouws. Uiteindelijk deden haar ouders haar op het Lycée français zodat ze haar Latijn niet zou verlezen, noteert Berenboom over zijn polyglotte moe. war Jiddisch werd gesproken. Met zijn hij Hidisch werd esproken. Met zijn vader sprak hij Hebreen ws of Aramees wanneer ze naar de synahij geel en opende later een apotheek in Schaarbeek waar hij Recca ontmoette. Zij was naar Brussel gekomen om auréat verder te kunnen studeren, $d$ 作 (940 Jebecca trouwen in mot en 'doos van Pandora' het dins wiis in t' 'Jodenr. wet feit dist ceft geetc de tekst eengrote neerwarde. Het verleent het de verteller men ijn seculier kosmoplitische nietreligeuze vade

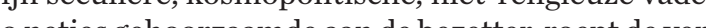
. Deho van de zoon

Dehoof leleden van Chain en Rebecca dat wordt verteld via bring et ware on iljst door mer luchtige stukken waarin Berenboom op zijn bekende ironische manier comHet hoofdstuk warin an de hand van espelingen. tike it de wer dertig it de doeken wortgedn. Verviers die op een avond de vrouw in de kist dardVerviers die op een avond de vouw in de kist daadbeeld De vader van Kuife is ook present niet alleen in in Berenbooms taal (de beroemde herhaling van de beeld. Het hectives Jansen en Janssen), maar ook in beeld. Het hoofdstuk over Chaims plannen om naar met Hergés migratien wort in verbailiê of tinië en met zijn stripalbum Kuifje en het zwarte goud waruit stipar goud waaruit een paar kaders zijn overgenomen in Molijkeur Optimiste. Berenboom speelthier eenvermaSijspeldeplanentanzijnvaderenhe Hergé en herinne-

De brieven van de familieleden van Chaïm en Rebecca moest Berenboom laten vertalen. Zo gaven che zijn voorouders. All deen zijn grootmoeder Frania moeder van zijn viler, wist uithet getto van Warscha, moeder van zijn vader, wist uit het getto van Warschau Het Het boek eindigt met een prachtige Proustiaanse herzijvanging 
de lezer de wereld van het shtetl ontdekken naarmate er een vertaalde brief bij hem arriveert. Zo kijken we als wer over zijn schouder mee. Zijn grootouders whke, over het aanleggen van voorraden, geldzorgen, boenerveresten, trouwpartijen, stille koude winters ct die dit die gestolde tijd wanin het eeuwenlang zweefde, die verstikkende cocon waaruit mijn vader z zijn zus onter (n) a (1) . rabet). Hierisnog no geleerden nodig, omdat de taal van de grootvader een lie nim is die niennand meer goed ontcijferen kan. Maar dankzij en te een Litouwse studente op het spoor te komen die de zoon zoon ontdelt de lezer dan hoe naief zijn groove

de korte hoofdstukje uit $M o n-$ sieur Optimiste is een graf in taal voor Sara uit Maków, en zus van diens vader. Chäm wo in nzinzus Esher Berenondingedos int in in Brussel heeft gevoegd en vertelt in haar brieven het verhaal van een jonge vrouw die niet wilde trouwen in het verstikende haar broer en zus, niet aardde, ter gkeerde naar Polen

.

Berenboons ans grés van W.G. Sebald die zijn verhalen over gevluchte Joderit taire fictie het leven wil opropen van anone taire fictie het leven wil oproepen van anonieme en in hun nienwe vaderland, wil Beren door heimwee in han nijn trekken tuss, wh Berenborm een doorgaande lijnn trekken tussen de eigenaar van de garende advot in Bussel. Hij heft zich met andere en de advocaat in Brussel. Hij heeft zich met andere worden ingeschreven in zijn fannillegeschiedenis en le hij wonderwel in geslaagd.

Désirée Schyns

\section{MEMORYLANDS \\ HERITAGE AND IDENTITY \\ IN EUROPE TODAY}

Sharon MacDonald

London: Routledge, 2013, 293 p.

"M

mory has become a major preoccupation - in Europe and beyond - in the twentieth century and into the twenty-first. [...] Europe has become a memoryland - obsessed with the disappearance of collective memory and its preservation (1): it is with these insightery word that cultural anthropologist Sharon MacDonald opens her lates getion of the conds. The book is an orignal investiand of the connections between hertage, identity and memory in contemporary Europe. In it, MacDonald provides the reader with numerous examples of how textupin identity and textualizing all this in a vast and interdisciplinary anthropogy and ethrography. nthropology and ethnography.

The first half of the book concentrates on how the European past is nowadays made and narrated, felt and then sold. Having introduced the subject of her rex alls the European memory complex, MacDonald first illustrates how anthropologist discussed the European past in their scholarly works and in a the European identity and EU symbolism - from the EU anthem to to the analysis of the relationship betwe She then moves to the analysis or the relation anthropology in the study of Europe, discussing the works of renowned scholars like Emmanuel Le Roy topics as different as collective id ortity in studied topics as different as collective identity in the rura Argonne region of France or post-Yugoslav Bosnian memostalgia are at the centre of the following chapter, where the ory especially objects, food and homes: from gardening ory, especially objects, food and homes: from gardening as a way of re-rooting memory among Greek Cypriots to nostalgia for Socialist-era commodities in contemporary Germany. As MacDonald notes, the memory phenomenon has also become a sort of business or at produced for tourists. This is the case of the heritag centre Aros: The Skye Story, opened in the Scottish Isle of Skye in 1993 or of the Slow Food movement, founded in Italy in 1996 and concerned with the preservation of local and authentic food products.

In the second haf of the book, Macoonald anaIn the lyzes specific dimensions of the memory phenomenon cosmopolitanism and lastly the future of meme, in Europe. Muse and lastly the future of memory in Europe. Museuns are a core conponent of the European memorial landscape and, according to the a powe ful medium that reflects "an active onging a powerful mervin that reflects "n active ongoing intervention into past presencing" (161). For this realif" (141) and various a "heur and local institutions (141) and various annateur and local institutions such as the Latvian Ethnographic Open-Air Museum and the Shy Museums chapters deal with issues oftranciltural heritage, with bring bring about in European identity, and then Holocaust conmory. Co memory. Concerning migrants, MacDonald first takes into account a controversy erupted in Vienna in 2007 was publicly displayed in the park of the Kunsthate was publicly displayed in the park of the Kunsthalle and then the activities of museums such as the Cite entionale de thivtire de explain how monuments and museums could articulate new and more inclusive ideas of Europeanness. port of the larger memory phenomeno part of the larger memory phenomenon and as a sort of memory imperative for European and non-Europea citizens of being that ways of being national. The future of memory in Europe is at the core of the last chapter, which tries to persistinto the future. For MacDonald it is vory will that this will be the that this will be the case, even though "new challenges curro the EU in the cost of today's the eu in the context to confrn this suggestion, highighting the need for a renewedsense yet multivocal idea of the past.

Even though Memorylands is largely based on articles originally published as separate papers, the autho and cod to asser subject, and as the author herself acknowledges in the introductory chapter, some areas are covered more than others: Britain and Germany - two places where MacDonald conducted fieldwork - feature prominently, as opposed for example to Italy or Spain to which little space is dedicated. In terms of topics, I would have liked to read a more detailed discussion of the memorial legacies of colonialism, especially with reference to France and the debates on the comprofoun of the Algerian War, which cleary have profori that he a so allowed and the West as and has shown.

This said, Memorylands is a timely and useful text that gives the readers a rich overview of the contemdiscussing much of tho pchorly literature neede in order to understand it. It will contitute need reading for students and scholars interes essential reading for students and scholans interested in memhistory.

Dario Miccol

\section{STORY OF A DEATH FORETOLD: THE COUP AGAINST SALVADOR ALLENDE, SEPTEMBER 11 ${ }^{\text {TH }}, 1973$}

scar Guardiola-Rivera

New York: Bloomsbury Press, 2013, 496 p.

the last few decades many scholars have examine the rise of Chile's President Salvador Allende and the subsequent coup against the democratically elected tion, Allende's notion of resista War and revolution, Allende's notion of resistance or la via chilena models. Within the confining definitions of the Cold War the global community viewed Latin War, the global community viewed Latin Americans 
communism. To many Latin Americans neither of these Iternatives provided true democracy. While Marxism undoubtedly offered Latin Americans a framework to critiqu U.S. imperialsm, the left in Latin America consistently created their own defintions of revolution and denocracy. Indeed, in 1970 Allende became the first Manx. Alenistery elected as the president of

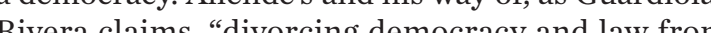
civera clains, "divorcing democracy and law from Cold War binaries. Allenege moved beyond stifling Cold War bice, andes. Ale the most significant examples of homegrown revoluthe US bycreatingauniqu form wor che insired by p.S. by creatinga uniqueform withinge inspired by particular historical processes Despite the exceptiones the US. his Popula Unity party as a dangierous Uis Popular Unity party as a dangerous challenge to ..S. hegemony and capitalism. In his well-researched monograph, Guardiola-Rivera provides one of the to power, the coup against Allende, and the res this

Guardiola-Rvera's work tells the story of Allend in three parts. The first concerns precedents an cxplores the intellectual influences of Allende how this inspired him to become a "true represe and ive for the people" (12). This inspiration crose tive for the people (12). This inspiration came from with political repression and revolutionary violions with political repression and revolutionary violence. different experie "revolution frombelow" Thvision a flich interes rect

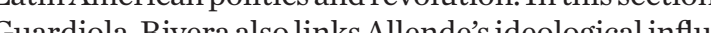

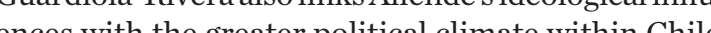
This wers a greater political climate within Chile. in rienced within his lifetime and also another layer to what could have been a standardbiography. The book is particularly strong when Guardiola-Rivera references

In part II the Coup the author focueva.

In part II, the Coup, the author focuses on the events leading up to Allende's election and the 1970 vote between right wing candidate Jorge Alessandr Rodriguez, a progressive centrist party, and Allende. looks at agrarian reform in Chile and Allende's Popular
Unity party in the larger context of the Cold War. He lso explores Allende's work with Chile's indigenous Mapuche population. As president, Allende promised the people he would "change the regime and system nd construct a new society" (158). Indeed, Allende planned to nationalize resources owned by U.S. captal, nationalize utilities, establish a minimum wage, top unemployment, and implement true agrarian War War proved much too threatening to U.S. hegemony. Chilean military officers with the hope of to contact Chilean military officers with the hope of orchestrating a coup. Guardiola wivera uses cli documents US was in sucrerting Allende's dem involved the In. was in subverting Allende's democratic election. In this section, which in some ways parallels Greg ica in the Cold War (University of Chicago Press 2004) cain the Cold War (University of Chicago Press, 2004) ights tha expran rights that emerged out of global post-war politics. Guardiola-Rivera argues that so-called developed rights but only within the narrow context of "civilized rights but only within the narrow context of "eivilized nations . According to both Grandin and GuardiolaRivera the non-Soviet left in Latin America offered Therefore in and a valid path for democracy. Therefore, in spite of claiming to support democracy hrow soven consistently attenpted to over-

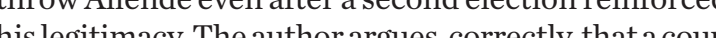
his legitimacy. The author argues, correctly, that a coup acy" (238). Indeed hum rights did not matter whe the nation was not considered part of the so-caled civilized post-war world Section cilly powerful when Guardiola-Rivera aly powerful whardied description of the events leading up to the coup and the unta's subsequent take ove

Section III, Aftermath and Consequences, which is shorter than the other sections, analyzes political action in Chile up to the present. It examines the ruling Junta and General Augusto Pinochet's "destruction (340) "(340). Guardiola-Rivera explores the two types of "nnd thency ordinances the Junta used for control author cobsequent destruction of human rights. The to events in Latin A gal significance or Nuremburg argues, "such legl preced during the Cold War. He - whether soldiers, civil sent lents no one means the individual liability of human rights violators cannot be easily shed in an emergency" (352). Thi powerful statement, like others in Guardiola-Rivera's work, connects the coup against Allende to larger historical events and violations of human rights in the $20^{\text {th }}$ century.

Though the book at times turns into abagioraphy The evident This evident. Thisbookisanexcellentchoice foranyone who wants to go beyond a general Alle influences within the complex history of Chile

Lindsey Churchill

\section{WAITING FOR MARCEL}

ORPHÜLS: THE LITERATURE

OF AUTHORITARIAN RULE

AND RESISTANCE IN LATIN

AMERICA

Becoming the Tupamaros: Solidarity and Transnational

Revolutionaries in Uruguay and the United States Revolutionaries in

Nashville: Vanderbilt University Press, 2014, 206 p.

The Ideological Origins of the Dirty War: Fascism Populism, and Dictatorship in Twentieth Century Argentina

Oxford: Oxford University Press, 2014, 216 p.

Memory and Transitional Justice in Argentina and Uruguay: Against Impunity

Uruguay: Agains

New York: Palgrave Macmillan, 2013, 319 p.

2010, at the XXIX Latin American Studies Association Congress in Toronto, the historian Steve Stern
called 1970s stated-sponsored terror in Argentina a "dirty war". An audience member self-identified as an "Argentine", speaking for "Argentines" scolded him.
"Dirty war", he told Stern, was a term invented by the "Dirty we dictorship, and as such, should never be used. Stern, perbaps the most authortive analyst f implicitly that policing langua brings us close truth on state terror. The moment evoked the manar in which some who use the Hebrew term "Shoph" cho "Holocaus" " for thei " putative che slaughtered by the Nazis.

As the international scholarship on authoritarian violence in Latin America has grown quickly since co, dowinant narratives have tended often to rige langua As in the use of the term "dirty war" there is ight and there is wrong. In this chilling contet investigators racing to fit their cases into these dis investigators racing to fit their cases into these discourse garded the on the evidence. Commenting on a museum opene Massa critic José Ramón Ruisánchez Serra writes, “despite critic Jose Ramon Ruisánchez Serra writes, "despite a genuine effort to create a site where the most cruin event in the second half or the twentieth century in Mexico could be commemorated [...] the museum

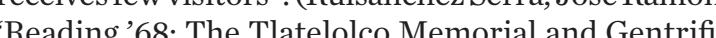
'Reading '68. The Thatelon' in Kenija Bilbij Gentrifcation in Mexico City', in Ksenija Bilbija \&. Leigh A. Payne (eds.), Accounting for Violence: Marketing Mem$2011,181)$ In trying to explain why Mexican visit this memory site to state terror, it never occurs to Ruisánchez Serra that his starting prever to Ruisanchez Serra that his starting premise may be wrong. Could it be that the powerful academic line that Thatelolo was both a unique and horrific moment of state terror in Cold War Mexico is inaccurate? Isit possible that most Mexicans may not stop by the museun because theydonot view Thatelolco as "the most crucia vent" or even as significant?

Much of the academic community addressing authoritarian violence in 1970 s and 1980s Latin America has not had a Marcel Orphüls moment. Some can't see grey zones on authoritarian rule - that the term "dirty war" can have multiple meanings or that The is reminiscent of Frens to differcal culture before the documentary Le chagrin pitié (1969) prompted an opening in how the French 
understood Vichy and Nazi occupation. Until the late1960s, a dominant, Gaullist narrative admitted only onememory of the French under Nazi rule. There were tho wo these who bersistence of that binary likely helped Socialist president François

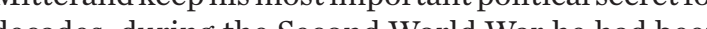
che both a member of the resistance and a Vichy bureaucrat, a combination so seemingly incongruous and so atds with post-war French memory making on the 1964, that woun 19. the can is pre and met. it is precisely that apparent contradiction and many others that must be resolved to break down

Of the three books reviewed here, two take

or the three books reviewed here, two take us licto whe cictat importance puls in the first instance in a rejection of the powerful tencen in the scholary literature to military rue (and resistan not nom tein's monter stin's monster emerging from American Cold War (n) transhation long term. Lindsey Churchills Becoming the Tupamaries between military rule and its oppo (n) case, the leftistguerilla group, Tupamaros). This is no apologia for authoritarian violence or a maligning of and and enpirically with the hypothesis that to take as a civen that military thus and their enemies were pola

Becoming the Tupamaros delves into the ofte poorly explained gendered abuse and humiliation of political prisoners in dictatorship-era Uruguay. Churchill shows the especially harsh, sexualized viothe ugly ferine the ugly feninization of male prisoners in gruesome the vis me but the book also explains both the violent military and the Tupamaro resistance as in Uruguan in Uruguayan society. At the same time, Churchill products of longer-term violon in Urug wer society. In their clandestine publications, for exam- ple, the Tupamaros excoriated military authorities for mprisoning male guerrillas in a general prison populamilithat of ase case of a young guerrilla who cut a gay man with glass wishe with sulted in mental illness. In this and other cases, the Uruguayan aft characterized imprisonment under the military and "prerous because of both "predatory" gay men

Both inside and outside prison, the revolutionary aft in Uruguay and elsewhere in Latin America frewith the dictatorship and with of homosexuality Weyond this, Churchill writes "like the Uru whole. Beyond t Chist nilitary [...] the Tupanaros supported the polariza-

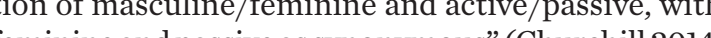
151). The sond 151). The sometimes-violentexclusion and suppression foritical divide rected homosexuality seemed invisible in post-dictatorship democracy because LGBT people frequently had to conceal their

Churchill also points out other continuities and connections between post-dictatorship democracy, military rule, and the revolutionary left where under列 Tup Tupamaros as progressive on the integration of women into political activity, upending notions of women as

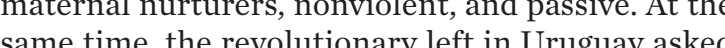
same time, the revolutionary left in Uruguay asked ity and to become socially constructed and femininity, and to becons socially roles as wives and mothers. Either way. "emomen' roles as wives and mothers. Either way, "embracing - dichotomous gender restrictions confined women" ditions political participation to constucted gender norms" Wurchill 2014, 153).

With the fall of the dictatorship in Uruguay and even more so in Argentina, an initial reconciliation narrative excoriated violence on both the far right term continuity through dictatorship by explaining the remarkable integration of the Tupamaros into peaceful democratic politics, leading to the election of one of their number, José Mujica, to the presidency in 2009. Remarkably for some, on the campaign, Mujica do wanted nothing to do with "the stupid ideologies that come from the 1970s..." (Churchill 2014 156). Some authors have tied the Tupamaros' transtion to electoral politics in the context of similar developments in Nicaragua and El Salvador. Churchill ha an alternative explanation that breaks down the notio the Tupatorship period as aberant. She argues the he Tupar a they were Cuba-inspired revolutionary Marxists. The unusual historical absence in Uruguay of powerfulecothe author calls extro the author calls extraordinarily malleable ideologies. The the Tupanaros un in the eably 1970s, many neof cespres members of (15). Unike othe 2014, 159). Unlike other leftist revolutionary group of the era, the Tupamaros never rejected everything about the United States, which, in the end, forms the backdrop to the widespeadpoplarityactossideologAlso

Also dismissive of the simplistic notion of dictato ship as a Cold War deviation, Federico Finchelstein' Ideological Origins offers a compelling and bold new answer to the question, was the military government fure and ams-cictotorip Argentine popular culthe and anong oppo was a of the dictatorship in the United States, there was a strong tendency to equate to the dictatorship drew first on a that approach to the dictatorship drew, first, on a tendency among some to isolate the period as aberrant - a horrific intermption to mode be permitted again. In addition, it was based on the characterization of the regine as Nazi/fascist by some in the international hich Jewish jour in the Jew jour own famous characterization ofhis ordeal as a descent into a new Nazism

Finchelstein's linkage of dictatorship to fascism i more thoughtful and compelling. An aberrant, violent fistorical morid not not define the dictatorship a ther Jews in and of itself. The regine's fascisten- dencies have their origins in longstanding Argentine deological and political traditions extending back t least through the 1930s, and transcending both democratic and dictatorial periods. This is especially ent in the construction of an internal, subversive nemy that concealed a foreign, intrusive presence. Drawing on 1930s right-wing tropes, at the time of the 978 FIFA World Cup of Soccer (held in Argentina), the vide acepted fartic "the wide sact (Fil ( fascistic ideals of Argentine nationalism the the junta leader and psychopa junta leader and psychopath Admiral Emilio Massera to wo the World Cup to Argentines as a defence of the real Argentif id I teos a victory over subversion.

Ideological Origins goes on to show another important and longstanding link between military dictatorfascicic tatorship objective of defending netione sovereignty and waging an internal war drew directly on tropes from Nazi an internal war drew directy on tropes from Nazi Germany and fascist Italy. All at once, in winnable, and could never really be over. This wa whable, and could never really be over. This new identify enmy was at the a time a forign War war became a value. The ferocity and absurdity of War both mobilized an enthusiastic population an drew directly on in argentina The latter had long held that dying for the sake of Malvinas was a battle for that aying for

Where Ideological Origins and Becoming The Where Ideological Origins and Becoming The Tupamaros dispense with dull binaries in trying to explain dictith Justice in Argenting and Uruguy is and Transitional Justice in Argentina and Unyuay is preoccupied with exactly the opposite - isolating dictatorship as grossly

The book asks, what is the relationship between transitional justice and memory? Francesca Less offers an unprecedented overview of theoretical and empirical literatures on amnesties, trials, truth 
commissions, reparations, and memory narratives. He understanding of the latter "is similar to what Steve Stern [...] defined as "emblematic memory', a frametiple human effors, conflictual and conpetitive, to give meaning" to collective, decisive, ompetitive, to give meaning" to collective, decisive, or transforpulicorsenipublic domins like themassmedia public or senipublic domains like the mass media, govpros musc, books, and telovision [..... [They are] socially constructed and selective, they are neither arbitrary conction con (Le 2013, 20-21). Emble tic collective cvents" (Lessa 2013, 20-21). Enblematic or collective memory in Argentir

In a chapter on transitional justice in Argentina (still ongoing after more than three decades), Less plitica mome" with what ser "political moment" represented in Néstor Kirchner's way from the impunity of the 1990s ald into a new away from the impunity of the 190s and into a new pew phase of judicia reckoning there were 262 coninition victions on dictatorship-era crimes and counting. The jook correctly ties political change in 2003 and a new ften-poignant memorialization of military re the newly built Parque de a Memoria Plata a Plata estuary to the hundreds of memorial plaques on sidewals th rou which people were "dother cities,

Chapters on Uruguay trace similar uplifting story Chapters on Uruguay trace a similar uplifting story wils collective, enteris calls collective, enblematic nentes were pitted a gainst dictatorship inpunity. Like Argentina, with he arive couste in the lall begin. Lessa casts Uruguay as under apall in the late 1980s and 190s, a memory or silence and over the need for truth, justice, repatriations, and (the need for (tessa 2013 218-219). As much as anything Memory and Transition-219). tice is a morality tale of two civil societies that have fice is a morality tale of two civil societies that have

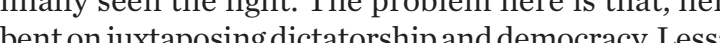
bent onjuxtaposing dictatorship and democracy, Lessa and memory, then runs with them for the length of the book. In linking the 1990s Argentine presidency of Carlos Menem, for example, to the memory of silence and oblivion, like other critics of that administration

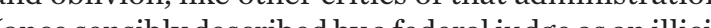
(once sensibly described by a federal judge as an illicit crime organization), Lessa assumes that the politic f in the in that there is still no study of participatory politics under Menem, whose presidential terms spanned a period of emocracy as open as that or the past fifteen years? Is it possible that what Lessa characterizes as ye

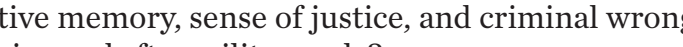
tary rule?

Beginning with her arguments on emblematic nemories, Lessa routinely assumes that there is a Uruguay that has fintly tristed argentina and Uruguay that has finally triumphed as a result of the current wave of prosecutions. There is simply no evieflection of political cultures in white, middle-class eflection of political cultures in white, middle-clas rrban enclaves in Argentha and of the Kirchner presiin in Rosario or Buenos Aires, or in rural Argentina. In (n) "Arume lective for the "hite ure middes that are only false "two demons" narative as contribessacites the and 1990 impunity in and 1990s impunity; instead of blaming the military for violent dictatorship, guilt was also parceled out to a second demon, left-wing guerrillas. It was only when that narrative was overco of military thugs) al blame squar " other false memories of dictatorship that a prope judicial accounting and the new round of prosecution could begin in earnest.

Lether or not working Argentine living in the one million strong, largely impoverished Florencio Varela municipality in Greater Buenos Aires ascribe or ascribed any blame for 1970s politjoignat issue is the rither-or binary of two more poignant issue is the either-or binary of two demons natory dichotomies in white, middle-closs Arsentinnatory dichotomies in white, middle-class Argentine political culture that negate alternative narratives and working people of colour in Varela and hy which working people of colour in Varela and hundreds of Thstem, a dominant nar ative that accor of "appropriate" remembrance (that is to say, Lessa's emblematic memories that supposedly join Argentine and Uruguayans across class, race, and geographica boundaries in common recollection) is that those who don't have the correct memories are ignorant, and condemned to "oblivion".

While racialized class differences shape society throughout Latin America, unlike Guatemala and Chile, state terror in Argentina and Uruguay was not directed in the first instance at working people of color. In thi context, most Argentines lived through thedictatorsh not in sympathy with authoritarian rule, or especialy preoccupied with whilher violence tatorship or the guen itin all regards andinacontext during the dictatored and in defore military rule, dung and whout sig champion boxer Juan Martin Coggi ren Friday evenings as a young teen-ager fighting in the rean gen much bigger and stronger than him. He made money from accomplices in the crowd bettingsuccessfully on his improbablevictories. One night in 1976, Coggi to ned ped a were un were what happened next. Nothing, he answered. They all Inack and the fight started again.

In an interview that had lasted two hours and had covered the dictatorship period, this was the first and only reference to military dictatorship touching the ives of people in Brandsenor Cogginimself. To Coggi, and millions of poor, working Argentines of colour, state terior was incidental to their lives bearing hor mor mo lence. Their memories and narratives of dictatorship what thergen id the-class memory-1978, and have been told by midde-class menory-making institutions (often is ignized by acadenics) that their neno "oblivion" is ignorance. For those who have yet to feel the impact there is the-hum rigatent disdain. The architect the new pro-human rights Argentina, president Raúl Alfonsin, if his post-dictatorship hurs rep rights her the Bus post-cictator ho poverty and runaway inflation in the 1970s and 1980 asked me rhetorically, "I wonder if anybody at the funeral shouted, "hey Alfonsín, and the price of milk?", She was evidently stuck in oblivion.

David M. K. Sheinin

TO WAR. A JOURNEY ALONG THE FRONT OF WORLD WAR I

Arnout Hauben \& Johanna Spaey

Antwerpen: De Bezige Bij, 2013, 272 p.

nfotainment is supposed to disseminate historic nowledge to a broader audience, and I am fully aware that this unavoidably implies the loss of some pure favour of the genre's entertaining aspect. The problem with Arnout Hauben and Johanna Spaey's

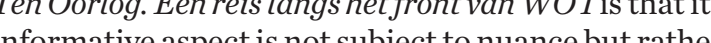
tertive aspectis no ed by inaccuracies.

Afew preliminary remarks. Reading the title raise some suspicions: the subtitle, A Journey Along the Fe focus will be soly on the Western Front in Europe, neglecting the iven, which is an a ceration may have been deadlocked for years, but the summe may have been deadlocked for years, but the summer and the the do "ine” is a biased view on a geographical abstrectionteven, or especially when one unwittingly adheres to

, or especially, when one unwittingly adheres to it A to call the televion program tate to call the television programme a documentary to Compouben's previous tour deforce, ajourney on foo that the genres of the road trip and the pilgrimage that the genres of the road trip and the pilgrimage will cavily influ heavily influenced, via the TV show, by the visual arts: the imentaries use static shots and wide views such as the image of a horizon to depict a clear and complete aesthetics relate to the books documentary cla ans. 
Luckily the authors are aware of their at once extensive and limited approach. They do signal that the Westem Fin and that (Belin) (11) As (hited this front (11). Assuch, the tales of the Italian Grant an the vative inclusion for a Belgian target audience. The ars was not only fought by young white men. Hence, it do was not only fought by young white men. Hence, it does

It also makes explicit claims of causality as to the (in thence such

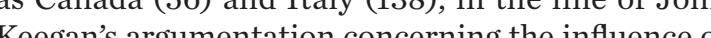
keegan's argumentation concerning the influence of f Battle (Lon post war Bitish society in The Face f Batle (London: Pinlico, 2004). As such, it touch pon the relevance of the Fist Word War and its cher for mosa sect biblion on the war the readers hungry for

Finally, the book is unsurprisingly reader-friendly and at tines attenpts to include an authentic lolancholic beauty. The frequent citations of egococunts, such as le tess ho the and diary entros, to undermine the contemporary war propaganda by iving a voice to its victims, wishing to illustrate by confict's inhumanity and futility Of reater contion their son in a dion their son in an accident and who subsequently started colv. The shells may been as "transeping gy. The shells may be seen as a "trangenertiona metonymical strategy", which is ultimately, of course, cooned to fall "De be "Thoetimmens zijn, net zo groo ( of what the authors attempt: one may try to come wips with the past and fill the hole that this past has grips with the past and fill the hole that this past has

Yet this emotionally powerful insight is rendered ad absurdum through Hauben's exaggerated selfEmpathy is a with the soldiers on the frontlines. Empathy is a necessary attitude when undertaking a journey of this kind, but the parallels that Hauben draws between his crew and these soldiers are not. The is playing the Last Post, while the crew of three kisses and hugs their girlfriends, wives, and children goodbye, "zoals elke jonge soldaat die in de Eerste Wereldoorlos "zoals elke jonge soldaat die in de Eerste Wereldoorlog
naar het front vertrok" (23; "just like any young soldier naar het front vertrok" (23; "just like any you
who left for the front during World War I")

Another scene, in which Hauben draws a paralle between the artillery fire directed at Reims in 1914 and the thunder over that city anno 2013, suggests the a was a would-be soldier. While this move caters to current expectations regarding the participatory nature of television, more critical distance and attention to the sion is required.

However, this problematic attitude is in my opinion not the book's greatest flaw. Even more aggravating are the numerous factual errors and contradictions. the nare the byproduct or the attempt to illustrate leads to the une leads to the usage of contradictory maps or picture from handingen ing that the frontlines did not ing that the frontlines did not move during four years. Also, the depiction of the fronthines east of Reims is this city through (78) indicates the trenches ran from this city through Chanpagne-Ardenne, Lorraine and telijke, whereas the text argues that [h] et meest oostelijke decl van de "ranse "tronthie wordt gevorm door Lothan ( French frontline is shaped by Lorraine"). One may argue that Alsace was indeed German territory from 1871 untill A18, yet this is not indicated on the map nor entioned in the text.

Another example of this impreciseness is the description "cille Belgiansectorin the frontline around Diks Somme two Somme, two years later. (32) Finally, on at least one occasion the information provided is inaccurate: two German during World War II, supposedly by Am Germany during World War Il, supposedly by American in Spitfres. The authors are apparently unaware that To the Grict To the German survivors this makes no difference of course, but one might have hoped for a correction from the authors. Evidently it would not be very tactful to confront the survivors with such errors in the miniseries. The book, however, did offer the opportunity to rectect on the extensive use of eyewitness accounts in differing standards of historical truth.

Add some minor mistakes, such as a translation error in Rudyard Kipling's My Boy Jack (71) and the mention of presumably lesser-known facts without providing background information (e.g., the presence of Russian troops in Reims), and it becomes clear that this book cannot live up to its documentary claims. in , contradictions and conjectures are also found in docum Sebald and Al the ar Knge-they even constitute the backbone of the authors poetics. The problem with Spaey and Hauben's narrative is, however, that it does the contris the contradictions do not appear as an enlightening appeal to the reader's perspicacity. The book is rather meant as light-hearted entertainment, in line with the his respes. The genre of the road the is significant in this respect, as is to homage to those fallen and those marred during an after the war and thereby continues the tradition of ough a alysis of the war's causes and cons. A tho is nearly completely abs causes and consequences is bloody nature or the war is blamed on the high-tech art of war are-nothe war is blanged In spite of the inclusion of overse occupation. In spite of the inclusion of overseas troops and labourers, the (very few) Congolese troops on Be gian soil are - rather oddly - not mentioned, nor are whose desor wise descendants (also) live in Belginn. There ing the war stories of Belgium's new citizen' ing the wastor Again, they are denied access to our (Belgian) practices of commem an adhering to the all-soldiers-are-saints harrative, the authors which is a shame. The inter would is a shane. The interest of a broader audience would nothave waned, since the book's road-trip structhe various emotionally powerful an theatres, and the various enotionally powerful anecdotes would " have uncer the perfect counterweight to such "dry" and uneasy remarks. Dry, because on a meta-leve view on World War I and by hint at social din our view on World War 1 , and may hint at social debates related to ethnicity anno 2014.

In general, this book had a lot of potential, but suffered from the aut bors' tion, which undermines the credibility of their work. This is telling of a broad cultural interest for this conbecome persistent myths. Surely, a methodologically crestre hould wor is, sadly, frustration

Tom Vanassche

\section{THE SLEEPWALKERS HOW EUROPE WENT TO WAR} IN 1914

Christopher Clark

London: Allen Lane, 2012, 736 p

014 is not just a year like any other: it carrie the commemorative weight of crisis, war, an tion, freedom and new beginnings. 2014 repreents the janus-faced character of the modern era whe- life-changing innovations evoked alongside f three significat dates in modern history bring of three significant dates in modern history bring through which abont today came into being. This year, we com we live in the comer the ing of the American troops on the coast of Normandy the Wall in 1989. All these dates mark cornersto public memory cont public memory of contemporary Europe, and strongly rian 1914,1944 a 1989 , Europewas bo triangle of 1914, 1944 and 1989, Europe was born as reaction to the disive forces whin foundetion were laid to the (seemingly) peaice. The foundations were laid to the (seening peaceful and In 2012 , histo we know today.

In 2012, historian Christopher Clark published a monumental work on the origins of World War in Europe. The catchy title The Sleepwalkers - How seeks to break with a tradition which holds an impor- 
tant spot within First World War research: the almos paradigmatic effort to name a culprit, to acuminate the ful ful and unmistakable guilt. Clark explicitly refuses to arrange the profusion of sources in a way which supports any teleological narrative. He writes: There is hend (561) According, his work his work aims to retrace the steps which led to cer-

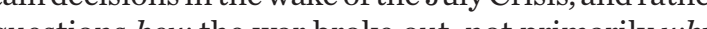
questions how the war broke out, not primarily why. The bision one decision affected the other. The result of this chai of reactions was - in its total scope and minacious outThe Sleepwalkers closely examines the structure of the Sleepwallers closely examines the structures of power within Europe, poses questions of where this c "stealily building cau thus challenges the notion of "steadily building causal presure (xxvi) which led to an "inevitable" war.

In his introduction, Christopher Clark starts with the time-and-again string Ar erchere ess of Hohenburg, to the unleashing of an inferno that with this steme misht already raise a sus within the statement might already raise awareness riod the attentive read period between the event and the outbreak could just be an excerpt, a detail from an utterly more complex clark dingeringin the background. In the following Crying to take up the ma hold argunen thing to take up the him that so many before him have produced, and weave them into a cloth that lacks apologetic moments or of souros, which often. Faced with an oversupply valid information, Clark describes a "world war of valid infors" surounding the matter (xxi). En of documents" surrounding the matter (xxii). Entire ials, politicians and key decision makers eved the war was end and the treaty of Versailes signed. These was ended and the treaty of Versailles signed. These official records, however, are frequently characterized by "tendentious omissions" (xxii). Memoirs absolutely uninformative, and even if their "little recolbstion" proved valuable, the protag their "ittlerecolconcerned with self-justification (xxii). It is the often representatives, their roles and their position within the ephemeral, but rather obscure power structure in heir respective countries that Clark carefully revisits. The Sleepwalkers is divided into three parts. The The developing argument will undertake in the following. Part One readjusts our "common knowledge" of the Sarajevo assassination as being the point-of-origin of the jeve as eve his wife were turned into stories, which took up a life their anideology was built. In fact, the seed was planted long

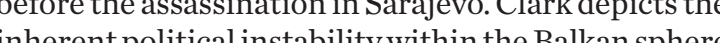
hich halican sphere which had been a reason for internation thons for decades. Furthernore, he sheds a light on the political tens surrounding the oring of war are located withindantly clear that the origins of war are located within continuing irredentist discourses and endeavors of Balkan nationalism in general, and South Slav nationalism in paridentity ling wear of Serbian identity being cons

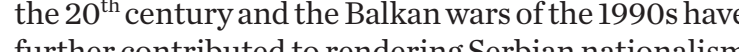
further chistorical for a historicalore the development of Clark's argument by a dissecting of maps, alliances, and international relations. The narrative skillfully establishes a pattern of ententes and allances, and the development of the crisis. Indeed, the Germanthe Entente Co the Franco-Russian Alliance of 1894 the Entente Cordiale between France and Britain in 1904, and the convention of 1907 between Britain and Russia, are structures whose allegedly indubitable relations are only visible in retrospect. Part Three count down that were not taken) which led to the (or decisions that were not taken) which led to the outbreak As Thu wa 'S As Thomas Laqueur ('Some Damn Fooling Thing', London Review of Books 35(23),2013) has also observed, the title The Sleepwalkers does not support the point that Clark is making here. In his introduction, Clark that decisions makers undertook in the moted steps" weeks preceding the outbreak ook in the months and "calculated steps" do neither constitur (xxvii). These "calculated steps" do neither constitute sleepwalking
Clark make any attempts to exonerate the protagonists from failing to take conscious decisions. Nevertheless, from failing to take conscious decisions. Nevertheles Christopher Clark is a master of his sources, balance with represbalances then with representing scenes and episodes in an almost to topple over a languare that keeps the reter cientific distance. The author balances the proporscientific distance tion between developinghis theory, his argument, and thus deploying methodology - and the steady flow cought to prose the layers of agency in The Sleepsought to expose the layers of agency in The Sleepwalkers, his norrative is saturated with agency of the historian. However, Cla touch historian only in passing. He acknowledges that acces to First World Wa naratives and heconclusions that we contenporaries draw are a natter of viewpoint, (re) an (re) make. Adiscussionofhis role, that ofthe historian, as an architect or history in the making seems utterly the master narrative of exclutes to deconstructing the master narrative of exclusive German guilt. That thing which Clark is thing which Clark is unawa it important enough to elaborate on. The question of guilt is closely connected to Gernan self-awareness identity were consted a tion Clat mentions this debate had on the reevaluation of Nazismet this debate had on the reevaluation or Nazism and the Third keich. A constructive fom the author on

In his introduction, Clark already makes one of the most interesting points. He reframes the First Worl War as a "modern event". A modern crisis, in his terms, is char acterized through the existence, "suicide bombers and a cavalcade of automobiles" ( $x \times v$ ), thus shook the world during the 2000s. He goes on:

Behind the outrage of Sarajevo was an avowedly terroris organization with a cult of sacrifice, death and revenge but this organization was extra-territorial, without clear gegraphical or wollical location, it was scattered incells across political borders, it was unaccountable, its links to any sovereign government were oblique, hidden

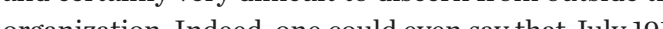
ene could even say that July 19
Sless remote from us - less illegible - now than it was in the 1980s. (xxv)

Yes, modern warfare, if you may, is characterized hrough scattered groups which base their raison-d'être on rather conservative world views and rigid morals pretending to defend their formative principles. Clark' modern enemy has become abstract, impersonal, sleeper or fanatic amidst us. Clark did find some striking similarities between the Black Hand of Serbia the suicide warriors of the $21^{\text {st }}$ century. Howeve first and foremost, in my opinion, the July Crisis is modern event because it already entailed the doom of the national concept. It heralded the end of the nation, for it cas the sed of supranational stros Clark has convincingly shown, the key decision. C hand, for wed to prevent intrusions into the and, alliance on the thinces on the other. As a consequence, the entire ystem doxically, posed a looming threat to itself. It was charchen

That initelf might notbeasurpise or ane

That in itself might not be a surprise or an extraordinary conclusion, but it already opens up a range in prading and regard to contemporary co war, in particular with regard to contemporary controis a resut of many of the es that Clon. Burope is a result of many of the aspects that Clark reiterates; it is a supranational structure which seeks to bridge nationalinterests and provide an overarching peacefu narrative that was absent in the years preceding the uropean founding narrative has become more and European founding narrative has become more an more contested. In 2014, Russian neo-imperialism or Putin's opportunism has led the European realm at the brink an the Uning in the the Ukraine and the EU might lead to a furthering of power inbalances for the benefit of the Western culture, and to a strengthening of perceived European cibly ciblyanis

The recent success of anti-European populion. The recent success of anti-European populism casts another dark cloud over the EU project, pointing at an unsettling tendency to reiterate the concept 
of the issues that people may have with the European union, one aspect remains striking: although we might find ourselves in the era of many "posts" - postof the nition is by no me of the nation is by no means dead. The threat to stop sacing national superiority and independence on the altar of the Europeanom (fnity became a mighty (n) itself standing at the abyss. The for shadowing of countries being ready torestrain the influence of the EU on the the alleged certainty of allian was worn the weeks preceding the war. Clark claims that supraplicy ming were non-existing in 1914, and that the policy making were non-existing in 1914, and that the ence due to mutual distrust and anbiguous politics. In the European crisis we encounter today, many of those hips between the ships between the European players are again oscillating inters gan a the the conclusions that Christopher Clark has reached alarmingly remind us of the reasons why Europe exist doing so.

Of course, the publication of The Sleepwalker predates the Ukrainian crisis. Nonetheless, one migh What are the imese question to Christopher Clark What are the implications of his work for the postWhat is the role of the historian in contruling What is the role of the historian in constructing and What minteritu which were a direct result of the World Wars?

Hanna Teichler
THE POSTCOLONIAL MUSEUM:
THE ARTS OF MEMORY AND THE ARTS OF MEMORY AND
THE PRESSURES OF HISTORY

lain Chambers, Alessandra De Angelis, Celeste Janniciello, Mariangela Orabona \& Michaela Quadraro (eds.), Ashgate Publishing Limited, 2014.

Postcolonial Museum makes an attempt to highlight the convergences between the discipline of museology and that of postcolonia theories and discourses. The various examples in the volume show that museums in today's age of postcolonialism and globalization have to be rethought and be introduced, in order to incs and techniques could be introduced, in order to incorporate transcultura and transnational experiences into the domain of the already existing structures of curatorial work. The book not only presents alternative ways of artistic and the West but a interactions between the East to the West, but also urges the need for museology to break away from its traditional mode of displaying immobile objects in a manner that only offers a linear narrative of past events. The functioning of musetermin heterotopias (the editors borrow Foucault's terminology) allows them not only to accumulate proct and expose - objects but also to contain time in a certain place. Dynamics of materiality togethe with aspects of temporality and spatiality thus become their basic characteristics. Given that museums are traditionally regarded as being embedded in imperial discourse, what is their role in current tines? Or to quote the editors. "How do museums 'decolonize' Thelves?” (11)

The Postcolonial Museum is divided into five parts and in total consists of 20 chapters. The first part illustrates the changing order of museums through time from the period of colonization up to present day postcolonialism. Interestingly, the first chapter "A Museum Without Objects" presents the project of the Maison des civilisations et de l'unité réunionnaise (MCUR), museum in French postcolony Réunion, and illustrate how the project, after a decade of its installation, was ended in 2010 by the new government. The failure of a project that dedicated itself to representing contact cultures in the region of Réunion, is indicative of the predicaments and challenges museums aroun the world have to face. Indeed, the new government of Reunion considered the MCUR as "useless an unnecessary, a waste of money "(37),particularly whe re re be realized. This case problentizes the fragile relationshipbetween arts and politics, withovernmenta politicia did in fact not see the politicians did in fact not see the importance of the per that the island has undergone through the past four decades, thereby prov

The chapter "Ethnograhic Museum: From Cultural Exposition to Intercultural Dialogue" is equally interesting, for it intodus pertes the impor nography into museology and states theinportance of The The article gives thexanis the Muséc des Civili Marseille and looks into ways in which muceums no merely consult tures converse with turesconverse with one another (64). The relationship between redefined in this dialogue, as the objects of other cultures are represented as works of art. The example of museums are challenged to find new ways of inean morating are challenged to find wew ways of "us/them" story. "us/them" story.

Part two and three of the book examine the association of arts with memory and performativity. Examples of museums and exhibitions across the world (e.g. Tate Museum in London, Palais de Tokyo in Paris, pop-up exhibition in Mahasthangarh, an installation in Maryland) are given to show that museums are formation in the contemporary "age of migrations" formation in the contenporary age of migrations" (99). One of the main innovations is the "performing" mays of which, as an alternative to the traditional direct and engaging interaction between and visitors. The performan vary from and vistors. The performances vary from actual theatrical representations to storytelling and hands-on strategies, where visito to souch the Whects at display (100).

Whereas the first part of the book presented a historical view of museums and traced its development native Archives" suggests innovative ways of dealin with issues of artistic representation, such as the video research creation titled Egyptian Chemistry. By investgating the chemistry and agro-ecology of the Nile, the iveolays its focus on human and non-human realities there conceiving of a "new form of materialistic un vers (218) that moves away from anthropocentric pertors ives and stimesses the importance of ecologica cientific concerns - the interrelationship betwo coning and mater - actually opens up tin

The Postcolonial Museum as a whole decidedly fill desideratum in the field of contemporary arts an production, as it ilustion tes critical aspects or artistic provion the encelo encounters in the age of globalization. In addition to and critical insights into the processes of curstoria wo forms of museum. The implications of the ana ses are far-reching and underline of these analyin are far-reaching and underline a paradigm shift in museology. Museums are now required to "open yet to come" (11). Could they turn from a place were ybjects are stored and exposed, as the editors suggest, to a space (according to Certeau's definition) thagest, to a space (according to Certeau's definition) that genSayma Khan 